\title{
Daily air temperature estimation on glacier surfaces in the Tibetan Plateau using MODIS LST data
}

\author{
HONGBO ZHANG, ${ }^{1}$ FAN ZHANG, ${ }^{1,2,3}$ GUOQING ZHANG, ${ }^{1,2}$ YAOMING MA, ${ }^{1,2,3}$ \\ KUN YANG, ${ }^{1,2,3}$ MING YE $^{4}$ \\ ${ }^{1}$ Key Laboratory of Tibetan Environmental Changes and Land Surface Processes, Institute of Tibetan Plateau Research, \\ Chinese Academy of Sciences, Beijing 100101, China \\ ${ }^{2}$ CAS Center for Excellence in Tibetan Plateau Earth Sciences, Beijing 100101, China \\ ${ }^{3}$ University of Chinese Academy of Sciences, Beijing, China \\ ${ }^{4}$ Department of Scientific Computing, Florida State University, Tallahassee, FL, USA \\ Correspondence: Fan Zhang <zhangfan@itpcas.ac.cn>
}

\begin{abstract}
The MODerate resolution Imaging Spectroradiometer (MODIS) land surface temperature (LST) data have been widely used for air temperature estimation in mountainous regions where station observations are sparse. However, the performance of MODIS LST in high-elevation glacierized areas remains unclear. This study investigates air temperature estimation in glacierized areas based on ground observations at four glaciers across the Tibetan Plateau. Before being used to estimate the air temperature, MODIS LST data are evaluated at two of the glaciers, which indicates that MODIS night-time LST is more reliable than MODIS daytime LST data. Then, linear models based on each of the individual MODIS LST products from two platforms (Terra and Aqua) and two overpasses (nighttime and daytime) are built to estimate daily mean, minimum and maximum air temperatures in glacierized areas. Regional glacier surface (RGS) models (mean /-mean-square differences: 3.3, 3.0 and $4.8^{\circ} \mathrm{C}$ for daily mean, minimum and maximum air temperatures, respectively) show higher accuracy than local non-glacier surface models (mean root-mean-square differences: $4.2,4.7$ and $5.7^{\circ} \mathrm{C}$ ). In addition, the RGS models based on MODIS night-time LST perform better to estimate daily mean, minimum and maximum air temperatures than using temperature lapse rate derived from local stations.
\end{abstract}

KEYWORDS: glacier meteorology, ice temperature, remote sensing

\section{INTRODUCTION}

Air temperature $\left(T_{\text {air }}\right)$ is an important input for hydrological, ecological and climate models. Extensive studies related to recent global warming have demanded more representative air temperature observations, especially in high-elevation areas (Liu and Chen, 2000; Qin and others, 2009; Cai and others, 2017). Since the Tibetan Plateau (TP) is considered as one of the most sensitive areas in the world to climate change, it has attracted numerous modeling studies on hydrology and glacier changes (Caidong and Sorteberg, 2010; Gao and others, 2012; Zhang and others, 2013; Lutz and others, 2014; Gao and others, 2015). However, the data-sparse problem of $T_{\text {air }}$ is a limitation in mountainous areas (Zhang and others, 2016a), and can be worse for hydrological and glacier mass-balance modeling in glacierized regions such as the TP (Yang and others, 2011; Gao and others, 2012; Zhang and others, 2012, 2015). The wellknown temperature lapse rate (TLR) with increasing elevation is commonly used for $T_{\text {air }}$ interpolation ( $\mathrm{Li}$ and others, 2013a), especially in glacierized basins over the TP (Zhang and others, 2013, 2015; Immerzeel and others, 2014; Gao and others, 2015). However, the TLR can vary both temporally and spatially (Minder and others, 2010; Li and others, 2013a). In reality, the limited number of stations within or near a mountainous river basin may create large uncertainty in the representativeness and accuracy of the estimated TLR, mainly because most stations are located in valley and lowaltitude areas (Zhang and others, 2016a).
Land surface temperature (LST) is an important variable in the studies of land surface physical processes (Wan, 2008; Li and others, 2013b; Wu and others, 2015). To alleviate the data-sparse problem, remotely sensed LST data have been widely used for $T_{\text {air }}$ estimation based on the strong correlation between LST and $T_{\text {air }}$ in mountainous areas around the world (Fu and others, 2011; Benali and others, 2012; Kilibarda and others, 2014; Kloog and others, 2014; Good, 2015; Zhang and others, 2016a). Compared with the limited station observations, the use of satellite LST data is an optimal option for adequately characterizing the temporal and spatial patterns of LST in broad regions (Li and others, $2013 \mathrm{~b}$ ). Owing to the middle spatial and temporal resolution, MODerate resolution Imaging Spectroradiometer (MODIS) LST products have been successfully used in various fields including surface radiation (Bisht and others, 2005; Wang and others, 2005), evaporation (Tang and others, 2010), urban heating island (Imhoff and others, 2010; Pichierri and others, 2012), climate change (Qin and others, 2009; Cai and others, 2017), hydrological modeling (Wang and others, 2009; Zhou and others, 2015), lake surface temperature (Schneider and others, 2009; Zhang and others, 2014) and air temperature estimation (Benali and others, 2012; Zhu and others, 2013; Zhang and others, 2016a). MODIS LST products are generated using the generalized splitwindow algorithm developed by Wan and Dozier (1996), with accuracies better than $1 \mathrm{~K}$ on homogeneous surfaces (Wan and others, 2002; Wan, 2008). Careful validation 
and evaluation of remotely sensed LST data is the basis of efficient application (Bosilovich, 2006). Validation of MODIS LST over various vegetated land cover types such as grasslands, pastures, forests and croplands shows relatively low accuracies with root-mean-squared-differences (RMSDs) of 1-4 K owing to a lack of accurate observations of emissivity and pixel heterogeneity (Bosilovich, 2006; Wang and others, 2008; Wang and Liang, 2009; Li and others, 2014; Krishnan and others, 2015).

MODIS LST data used in cryosphere science are applied mainly for validation and evaluation in Greenland (Hall and others, 2008a, Koenig and Hall, 2010), the Arctic (Langer and others, 2010; Westermann and others, 2011, 2012) and Antarctic areas (Hall and others, 2004; Scambos and others, 2006; Wang and others, 2013b; Meyer and others, 2016). The TP has an average elevation of $4000 \mathrm{~m}$ and extensive distribution of glaciers (Yao and others, 2012). It is also referred to as 'the Third Pole' outside the Arctic and Antarctic regions (Qiu, 2008). The previous validation and accuracy evaluation studies of MODIS LST data in the TP are focused mainly on vegetated land cover (Wan and others, 2002; Yu and Ma, 2011; Wang and Min, 2014; Min and others, 2015). However, the performance of MODIS LST on glacier surfaces in the TP remains unknown because of the limited temperature measurements in glacierized areas.

In this study, we comprehensively evaluate the performance of MODIS LST for $T_{\text {air }}$ estimation in glacerized areas of the TP. MODIS LST data are firstly compared with ground measured LST at two glacier sites to evaluate the accuracies of MODIS LST on glacier surfaces. Both MODIS daytime and night-time LST data are further used for $T_{\text {air }}$ estimation. The estimated $T_{\text {air }}$ are evaluated with observed daily mean air temperature $\left(T_{\text {mean }}\right)$, minimum air temperature $\left(T_{\min }\right)$ and maximum air temperature $\left(T_{\max }\right)$ at each glacier site. TLR is commonly used for $T_{\text {air }}$ estimation in glacierized basins (Immerzeel and others, 2014; Zhang and others, 2015). For further evaluation, performances of the $T_{\text {air }}$ estimation from MODIS LST are also compared with those using TLR.

\section{DATA}

\subsection{Ground measurements}

Surface temperatures of four glaciers (Parlung Zangbo, Xiao Dongkemadi, Zhadang and Muztagh Ata) observed from automatic weather stations (AWSs) in the TP were used in this study (Fig. 1). The first three AWSs provide daily mean $\left(T_{\text {mean }}\right)$, minimum $\left(T_{\text {min }}\right)$ and maximum $\left(T_{\text {max }}\right)$ air temperature measurements; Muztagh Ata provides $T_{\text {mean }}$ only. The $T_{\text {air }}$ data were derived from $10 \mathrm{~min}$ sampled data collected by an HMP45C sensor with accuracy of $\pm 0.2-0.5^{\circ} \mathrm{C}$. The Xiao Dongkemadi glacier station also provides direct LST measurement through the use of an Apogee Precision Infrared Thermocouple Sensor (IRTS-P) with an accuracy of $0.3 \mathrm{~K}$ over the glacier surface (Huintjes and others, 2015). The Parlung Zangbo station provides half-hourly radiation data measured by a CNR1 net radiometer with an uncertainty level of $\pm 10 \%$ for daily totals (Guo and others, 2011). The radiation data were further used to retrieve LST based on the Stefan-Boltzmann law with the correction of emissivity. An emissivity value of 0.99 was assigned, which is well in the range of reference values used in other snow/glacier studies (Hall and others, 2008a, Westermann and others, 2012). It should be noted that only the Xiao Dongkemadi and the Parlung Zangbo stations provide directly or indirectly observed LST data. Detailed information of the four AWSs is given in Table 1.

In this study, to conduct a more comprehensive evaluation for practical application, the TLR method was also compared. To build locally reliable TLR for comparison with $T_{\text {air }}$ estimation using MODIS LST, $T_{\text {mean }}, T_{\min }$ and $T_{\max }$ data from 19 China Meteorological Administration (CMA) stations around the four glacier sites were used (Fig. 2a). Selected CMA stations around each AWS were indicated as 'neighboring stations' represented by red triangles in Figure 2a. It should be noted that all of the CMA stations selected are located in non-glacierized areas, whereas the four AWSs are set up on the surface of four glaciers far away from each other.

\subsection{MODIS LST}

Products of version 5 of MODIS Terra (MOD11A1) and Aqua (MYD11A1) LST/E Daily L3 Global $1 \mathrm{~km}$ Grid were used in this study. Both MODIS/Terra and Aqua provide two daily observations including one for daytime and one for nighttime. The two overpass times for Aqua are $~ 1: 30$ (Aqua night-time) and 13:30 (Aqua daytime) local time. For Terra, the crossing times are $\sim 10: 30$ (Terra daytime) and 22:30 (Terra night-time). The accuracy of MODIS LST is reported to be within $1 \mathrm{~K}$ (Wan and others, 2002). Each grid of MODIS LST product has a quality control (QC) flag ranging from 0 to 3 indicating average errors of $<1,1-2,2-3$ and $>3 \mathrm{~K}$, respectively. LST data with a QC flag of 3 were removed for this study.

\section{METHODS}

\subsection{Evaluation of MODIS LST on glacier surface}

In this study, MODIS LST data on glacier surfaces were evaluated in two ways. The first was to compare MODIS LST with the observed LST at Xiao Dongkemadi and Parlung Zangbo glaciers. This method is used most often in previous studies of snow/glacier surfaces (Koenig and Hall, 2010; Langer and others, 2010; Westermann and others, 2011, 2012; Hachem and others, 2012) because it provides a direct evaluation. The Pearson correlation coefficient $(R)$, RMSD and mean absolute difference were used as the evaluation criteria (Wang and others, 2008; Hachem and others, 2012). In the second method of evaluation, daily mean air temperatures were used to indirectly evaluate MODIS LST data at all the four AWSs, following studies in other polar regions (Hall and others, 2008a, Wang and others, 2013b). The Pearson correlation coefficient was used as evaluation measurement in this method.

\section{2. $T_{\text {air }}$ estimation using MODIS LST}

\subsubsection{Estimation methods}

The linear regression is the most commonly used method to estimate $T_{\text {air }}$ from MODIS LST because the method is conceptually simple and its results are easy to interpret (Zhang and others, 2011, 2016b, Benali and others, 2012). Several advanced statistical models have also been developed for more accurate estimation of $T_{\text {air }}$ such as random forests ( $\mathrm{Xu}$ 


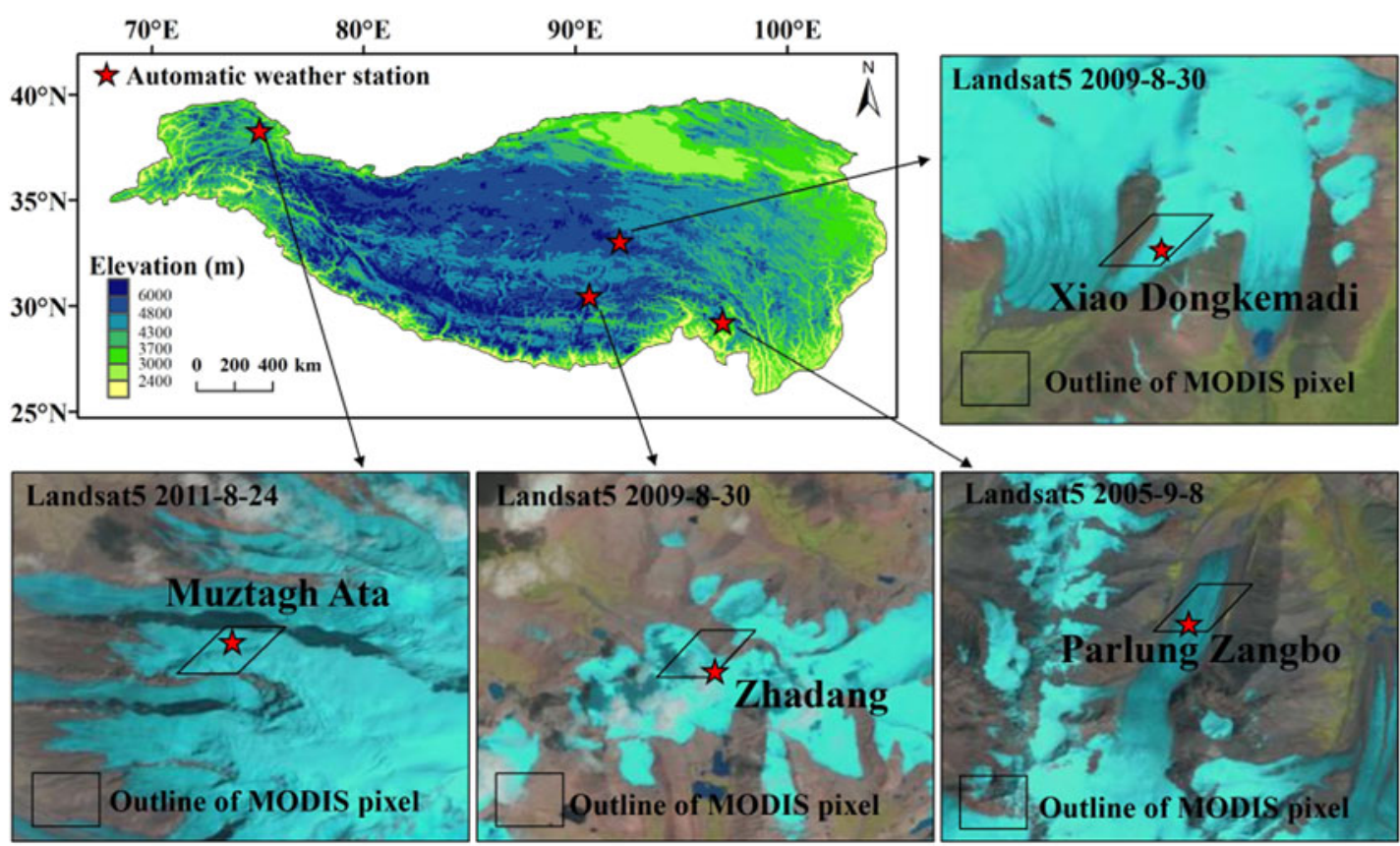

Fig. 1. Map of the Tibetan Plateau marking AWS locations. The Landsat images describing land covers in natural color modes with the capturing dates included. The outline of the MODIS grid is also plotted.

and others, 2014), M5 model tree (Emamifar and others, 2013) and cubist regression (Wang and others, 2014). However, the absolute differences of performance between these complex models and the simple linear regression are generally small (Meyer and others, 2016; Zhang and others, 2016a). In addition, given the limited sample sizes, complex or machine learning methods are not suitable for this study because they generally demand a large number of variables and samples. Thus, the method of linear regression that uses LST as a predictor variable was employed for $T_{\text {air }}\left(T_{\text {mean }}, T_{\min }\right.$ and $\left.T_{\max }\right)$ estimation in this study. It should be noted that, MODIS LST data have four instantaneous observations per day and four models for each station. The four models take Aqua night-time $\left(\mathrm{LST}_{\mathrm{AN}}\right)$, Aqua daytime ( $\left.\mathrm{LST}_{\mathrm{AD}}\right)$, Terra night-time ( $\mathrm{LST}_{\mathrm{TN}}$ ) and Terra daytime ( $\mathrm{LST}_{\mathrm{TD}}$ ) LST as predictor variable, respectively, as below:

$$
\begin{aligned}
& T_{\text {air }}=a_{1} \times \mathrm{LST}_{\mathrm{AN}}+b_{1}, \\
& T_{\text {air }}=a_{2} \times \mathrm{LST}_{\mathrm{AD}}+b_{2}, \\
& T_{\text {air }}=a_{3} \times \mathrm{LST}_{\mathrm{TN}}+b_{3}, \\
& T_{\text {air }}=a_{4} \times \mathrm{LST}_{\mathrm{TD}}+b_{4},
\end{aligned}
$$

where, $a_{1}, a_{2}, a_{3}, a_{4}, b_{1}, b_{2}, b_{3}$ and $b_{4}$ are all regression coefficients.

\subsubsection{Comparison of regional glacier surface and local non-glacier surface model}

$T_{\text {air }}$ estimation using MODIS LST is based on the empirical relationship between $T_{\text {air }}$ and LST, which is believed to be locally accurate (Benali and others, 2012). In addition, the $T_{\text {air }}$-LST relationship may vary depending on land cover type (Vancutsem and others, 2010). Since we here focused on the $T_{\text {air }}$ estimation on glacier surfaces, we first divided all of the available stations for each glacier into two classes of non-glacier surface (i.e. CMA) and glacier surface (i.e. AWS) stations. Regressions were built at each neighboring CMA station, and the best regression equation with the highest $R^{2}$ values was chosen as the predicting equation (i.e. model) representing non-glacier stations; this equation is referred to as the local non-glacier surface (LNGS) model. To conduct a fair comparison with the LNGS model, the local glacier surface model built by samples from local glacier AWS was not used for $T_{\text {air }}$ estimation. Instead, the best model with the highest $R^{2}$ values among the other three glacier AWSs was chosen as the model representative of glacier stations and referred to as the regional glacier surface (RGS) model.

The RGS and LNGS models were compared to determine a more reasonable and accurate $T_{\text {air }}$ estimation method using

\begin{tabular}{|c|c|c|c|c|c|}
\hline Station & Longitude/latitude & Elevationm & Mean annual air temperature ${ }^{\circ} \mathrm{C}$ & Time period & Available data \\
\hline Parlung Zangbo & $96.93 / 29.25$ & 4804 & -3.7 & Jan 2012-Dec 2012 & Radiation, $T_{\text {mean }}, T_{\min }$ and $T_{\max }$ \\
\hline Xiao Dongkemai & $92.08 / 33.07$ & 5621 & -8.6 & Jan 2009-Dec 2009 & LST, $T_{\text {mean }}, T_{\min }$ and $T_{\max }$ \\
\hline Zhadang & $90.65 / 30.47$ & 5800 & -7.9 & Jan 2012-Dec 2012 & $T_{\text {mean }}, T_{\min }$ and $T_{\max }$ \\
\hline Muztagh Ata & $75.07 / 38.29$ & 5900 & -17.7 & Aug 2011-Jul 2012 & $T_{\text {mean }}$ \\
\hline
\end{tabular}
MODIS LST. The better one was further compared with the method using TLR to evaluate the performance for $T_{\text {air }}$ estimation.

Table 1. Descriptions of the four automatic weather stations (AWSs) on glacier surfaces 


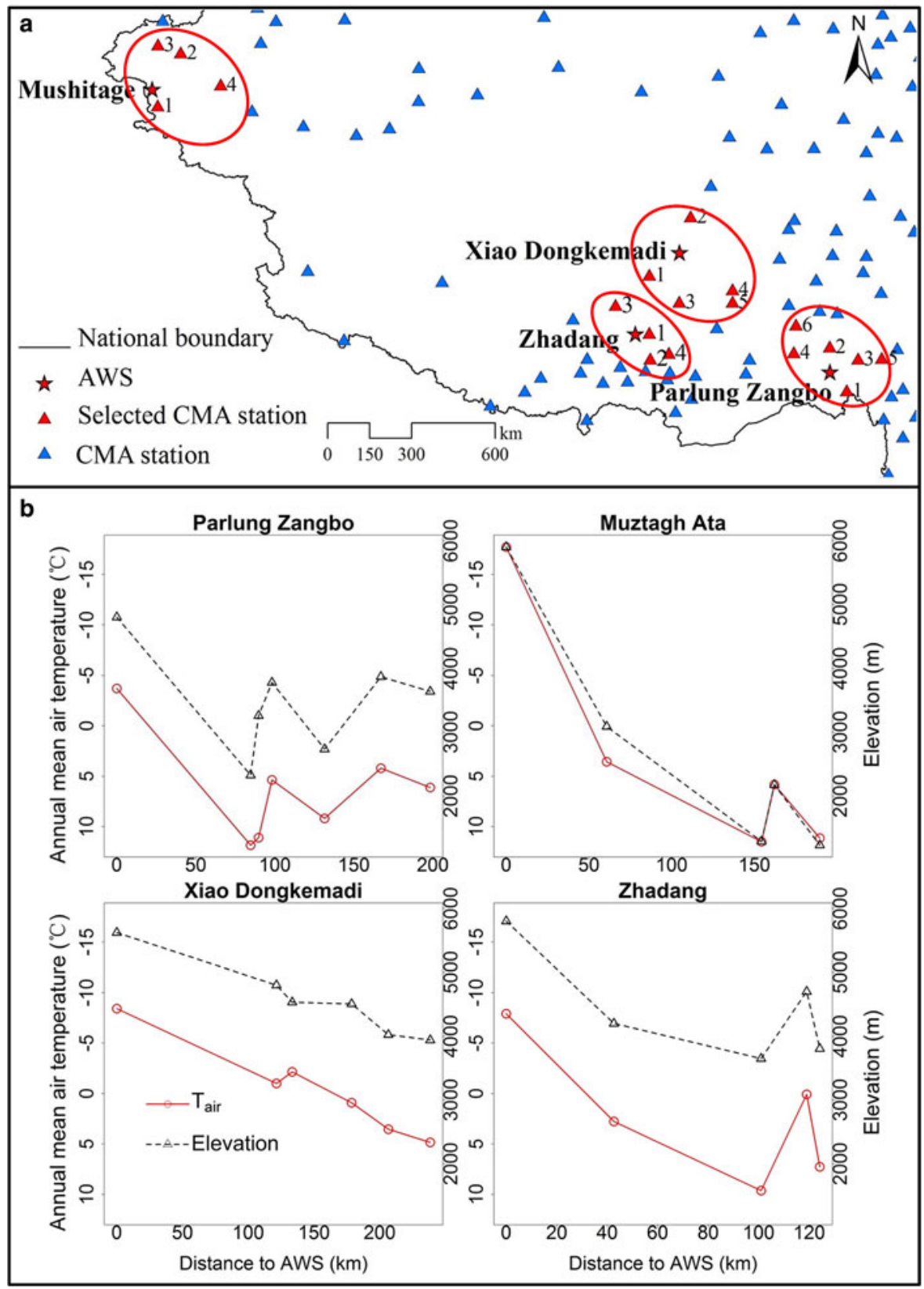

Fig. 2. Locations of selected CMA stations for estimating TLR for each glacier AWS (a), and their annual mean temperatures and elevations (b). The numeric labels in (a) are in order of distance to corresponding AWS. The annual mean temperatures in (b) are in the reverse order.

3.2.3. Evaluation of the estimation method using MODIS LST

Two approaches were used to assess the performances of MODIS LST for $T_{\text {air }}$ estimation. One is comparison with observed $T_{\text {air }}$ at glacier AWS and the other is comparison with $T_{\text {air }}$ estimation using the TLR method.

3.2.3.1. Evaluation by comparison with $T_{\text {air }}$ observations. RMSD was selected for the measurement of model performance (Zhang and others, 2011, 2016a, Kilibarda and others, 2014) by comparison with $T_{\text {air }}$ observations. To identify any significant differences among different models or methods, we used the Welch's paired $t$-tests based on the residuals produced by different models/methods following Williamson and others (2013). Mann-Whitney tests were also conducted for reference owing to the non-normality of the samples.
3.2.3.2. Evaluation by comparison with TLR. For comparison, TLR was estimated through linear regression on the relationship between $T_{\text {air }}$ and elevation (Li and others, 2013a, Immerzeel and others, 2014) based on neighboring stations around the glacier AWS by Eqn (5).

$$
T_{\text {air }}=t_{0}+t_{1} \times Z+t_{2} \times \text { Lat, }
$$

where, $Z$ is elevation; Lat is latitude; $t_{0,} t_{1}$ and $t_{2}$ are all regression coefficients, and $t_{1}$ is the estimated TLR. We considered the possible effects of latitude on TLR (Rolland, 2003) because the variation range of latitude for CMA stations around the four glaciers can be as large as 1.7-2.7 degrees. Since some uncertainties may be introduced by the possibly serious collinearity problems caused by adding latitude, the multicollinearity tests were conducted in this study. The variance inflation factor (VIF) is often used for diagnosing the multicollinearity problem and a VIF value $>5$ or 10 is 
generally considered to be serious (Stine, 1995; Craney and Surles, 2002). The test results showed that the VIFs for TLR regressions are all $<1.6$ indicating that the collinearity problem may not be big. Considering the spatial variation of TLR, a locally reliable TLR was obtained for each glacier AWS based on a sensitivity test on the number of neighboring stations. For each glacier AWS, stations within a $300 \mathrm{~km}$ radius were added one by one for estimating TLR in order of distance from the AWS. The smallest number of stations that passed the significance test at the 0.05 significance level was selected. Monthly TLRs were further built for $T_{\text {air }}$ estimation based on the selected stations.

When estimating $T_{\text {air }}$ including $T_{\text {mean }}, T_{\min }$ and $T_{\max }$ by using TLR, all data of neighboring stations were first converted to values at sea level ( $0 \mathrm{~m}$ here) using the TLR, and were then interpolated to the location of glacier AWS by using the inverse distance weighted (IDW) method (Jarvis and Stuart, 2001). The final estimate was calculated from the IDW-interpolated value at sea level to that at the elevation of the glacier AWS by using the TLR. Although previous studies show differences in the implementation of TLR, the performance was found to be similar (Stahl and others, 2006).

For independent validation and comparison, the glacier AWSs were not used for TLR building. For each glacier, $T_{\text {air }}$ observations from AWS were used as independent validation data for both methods, including that using MODIS LST and that using TLR. To conduct a fair comparison with TLR, only cloud-free days were selected for evaluation of $T_{\text {air }}$ estimation using TLR and MODIS LST. In addition, the results based on the four pass times of MODIS LST may not be comparable due to the non-corresponding days with different daily available LST data. Thus, a comparison based on days with four available daily MODIS observations was also conducted although the sample counts were limited.

\section{RESULTS}

\subsection{Evaluation of MODIS LST on glacier surface}

The comparison of MODIS LST with observed LST at glacier surfaces of Xiao Dongkemadi and Parlung Zangbo is shown in Figure 3. The RMSDs of MODIS LST on Xiao Dongkemadi $\left(3.8-5.3^{\circ} \mathrm{C}\right)$ were generally smaller than those on Parlung Zangbo $\left(5.0-12.5^{\circ} \mathrm{C}\right)$. With RMSDs of 3.8-4.9 and $5.0-5.8^{\circ} \mathrm{C}$, MODIS night-time LSTs recorded at $\sim 22: 30$ and $\sim 01: 30$ local time showed higher accuracies than daytime LST recorded at $\sim 10: 30$ and $\sim 13: 30$ local time with RMSDs of $5.2-5.3$ and $8.2-12.5^{\circ} \mathrm{C}$ at Xiao Dongkemadi and Parlung Zangbo, respectively (Table 2). Terra LST with mean RMSDs of 4.5 and $6.6^{\circ} \mathrm{C}$ showed higher accuracy than Aqua LST with mean RMSDs of 5.1 and $9.1^{\circ} \mathrm{C}$ at Xiao Dongkemadi and Parlung Zangbo, respectively. This result is similar to previous studies in which Terra LST are found to be more accurate than Aqua LST in the TP ( $\mathrm{Yu}$ and Ma, 2011; Min and others, 2015). In addition, MODIS/Terra night-time LST with an averaged RMSD of $3.3^{\circ} \mathrm{C}$ presented best accuracy in this study.

The validation results of high-quality MODIS LST (i.e. LST data with MODIS claimed errors $<1 \mathrm{~K}$ ) are also summarized in Table 2. The results are generally similar to those that did not exclude low-quality data, except that high-quality MODIS night-time LST at Xiao Dongkemadi showed clearly higher accuracies than all the MODIS night-time LST with RMSD decreases of 1.5 and $0.7^{\circ} \mathrm{C}$ for Terra and Aqua, respectively.
A comparison of MODIS LST to $T_{\text {mean }}$ observations at the four glaciers (Fig. S1) revealed high correlation coefficients of 0.78-0.94, except that low $R$ values of $0.44-0.61$ are observed for MODIS daytime LST at Parlung Zangbo. MODIS night-time LST with high mean $R$ values of 0.91 shows higher correlation with $T_{\text {mean }}$ than MODIS daytime LST with mean $R$ values of 0.78 .

\subsection{Evaluation of daily air temperature estimation on glacier surface}

4.2.1. $\mathrm{T}_{\text {mean }}$ estimation

Figure 4 shows significant differences for $T_{\text {mean }}$ estimation using the RGS and LNGS models. The averaged RMSD of the LNGS model is $5.0^{\circ} \mathrm{C}$, which is larger than $4.3^{\circ} \mathrm{C}$ of the RGS model. In particular, the performance improvement by replacing the LNGS model with the RGS model showed an RMSD decrease of 1.2 and $0.4^{\circ} \mathrm{C}$ for cases using MODIS daytime LST and night-time LST, respectively. Thus, the RGS models with better performance than the LNGS models were used for further analysis.

The averaged RMSD of $T_{\text {air }}$ estimation from the TLR method was $5.2^{\circ} \mathrm{C}$ which is larger than $4.3^{\circ} \mathrm{C}$ of the RGS model based on MODIS LST (Fig. 5). In particular, RGS model based on MODIS night-time LST showed relatively high and stable accuracy with an averaged RMSD of $3.8^{\circ} \mathrm{C}$, which is better than that of the TLR method. A fair comparison based on days with four available daily MODIS observations indicated that the RGS model based on MODIS night-time LST, with a mean RMSD of $3.3^{\circ} \mathrm{C}$, is superior to the RGS model based on MODIS daytime LST, with a mean RMSD of $4.2^{\circ} \mathrm{C}$ (Fig. S2), for $T_{\text {mean }}$ estimation. The RGS model based on MODIS/Terra night-time LST presented the best performance with a mean RMSD of $3.0^{\circ} \mathrm{C}$.

Figure 5 also shows that the methods for $T_{\text {mean }}$ estimation based on MODIS LST clearly outperformed those using TLR except for Xiao Dongkemadi, where a high accuracy of $\sim 2.1^{\circ} \mathrm{C}$ was obtained using the TLR method. However, the TLR method produced relatively low accuracies of $4.4-8.7^{\circ} \mathrm{C}$ at the other three glaciers, where higher accuracies of 2.7$7.5^{\circ} \mathrm{C}$ were obtained by the RGS model using MODIS LST, except for the RGS model based on Aqua daytime LST at Parlung Zangbo owing to the lower accuracies of LST (Figs 3, S1).

\subsection{2. $\mathrm{T}_{\text {min }}$ estimation}

Similar to what was found in $T_{\text {mean }}$ estimation, the RGS and LNGS models showed significant differences for $T_{\min }$ estimation with averaged RMSDs of 4.3 and $5.5^{\circ} \mathrm{C}$, respectively (Fig. 6). The performance improvements between RGS and LNGS models were significant with RMSD decrease of 1.8 and $0.5^{\circ} \mathrm{C}$ for cases using MODIS daytime and night-time LST, respectively. This also indicates the necessity of applying the RGS model for $T_{\min }$ estimation when using MODIS LST.

For most cases, significant differences were shown between methods using TLR and the RGS model based on MODIS LST (Fig. 7) with averaged RMSDs of 4.7 and $4.3^{\circ} \mathrm{C}$ for $T_{\min }$ estimation, respectively. The RGS model based on MODIS night-time LST showed an even lower mean RMSD of $3.5^{\circ} \mathrm{C}$. Days with four daily MODIS observations indicated that the RGS model based on MODIS night-time LST, with a mean RMSD of $3.0^{\circ} \mathrm{C}$, is superior to the RGS model based on 

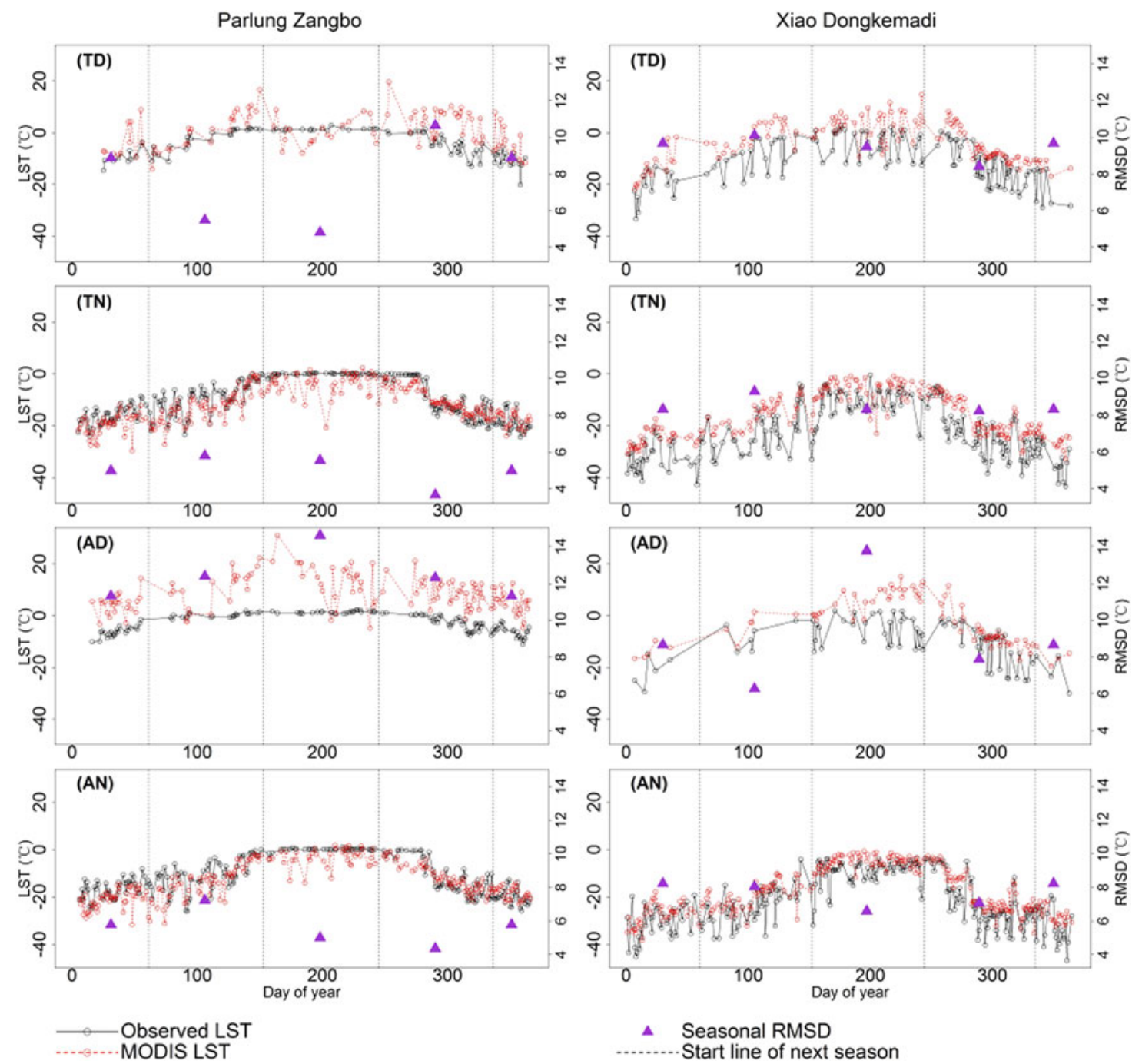

Fig. 3. Comparison of MODIS and observed LST at Xiao Dongkemadi and Parlung Zangbo stations. 'TD', Terra Day; 'TN', Terra Night; 'AD', Aqua Day; 'AN', Aqua Night.

MODIS daytime LST, with a mean RMSD of $4.7^{\circ} \mathrm{C}$ for $T_{\min }$ estimation (Fig. S3). The RGS model based on MODIS/ Terra night-time LST presented the best case with a mean RMSD of $2.9^{\circ} \mathrm{C}$.

\subsection{3. $\mathrm{T}_{\max }$ estimation}

The RGS and LNGS models showed significant differences for $T_{\max }$ estimation (Fig. 8). Both models produced obviously lower accuracies with higher averaged RMSDs of 5.3 and $7.5^{\circ} \mathrm{C}$, respectively, compared with $T_{\text {mean }}\left(4.3\right.$ and $\left.5.0^{\circ} \mathrm{C}\right)$ and $T_{\min }\left(4.3\right.$ and $\left.5.5^{\circ} \mathrm{C}\right)$ estimations. In addition, the performance improvements of the RGS model compared with the LNGS model for cases using MODIS daytime and night-time LST, with RMSD decreases of 2.0 and $2.5^{\circ} \mathrm{C}$, respectively, were both relatively large.

The TLR method and the RGS model based on MODIS LST showed significant differences in $T_{\text {max }}$ estimation for all cases

Table 2. Validation of MODIS LST at Xiao Dongkemadi and Parlung Zangbo stations. The number of samples $(N)$, Pearson correlation coefficient $(R)$, mean absolute difference (MAD) and root-mean-squared-difference (RMSD) are listed

\begin{tabular}{|c|c|c|c|c|c|c|c|c|c|}
\hline \multirow[t]{2}{*}{ Station } & \multirow[t]{2}{*}{ Type } & \multicolumn{4}{|c|}{ All data } & \multicolumn{4}{|c|}{ Excluding low-quality data } \\
\hline & & $N$ & $R$ & $\mathrm{MAD}{ }^{\circ} \mathrm{C}$ & $\mathrm{RMSD}{ }^{\circ} \mathrm{C}$ & N & $R$ & $\mathrm{MAD}{ }^{\circ} \mathrm{C}$ & $\mathrm{RMSD}{ }^{\circ} \mathrm{C}$ \\
\hline \multirow[t]{4}{*}{ Xiao Dongkemadi } & Terra Day & 130 & 0.84 & 4.0 & 5.2 & 39 & 0.79 & 3.8 & 5.5 \\
\hline & Terra Night & 207 & 0.92 & 2.5 & 3.8 & 94 & 0.97 & 1.8 & 2.3 \\
\hline & Aqua Day & 82 & 0.90 & 3.6 & 5.3 & 27 & 0.89 & 3.2 & 5.2 \\
\hline & Aqua Night & 251 & 0.88 & 3.7 & 4.9 & 124 & 0.92 & 3.2 & 4.2 \\
\hline \multirow[t]{4}{*}{ Parlung Zangbo } & Terra Day & 101 & 0.41 & 6.1 & 8.2 & 37 & 0.37 & 7.0 & 9.1 \\
\hline & Terra Night & 269 & 0.81 & 3.5 & 5.0 & 119 & 0.84 & 2.6 & 4.3 \\
\hline & Aqua Day & 136 & 0.60 & 11.5 & 12.5 & 34 & 0.13 & 10.9 & 12.1 \\
\hline & Aqua Night & 239 & 0.77 & 4.3 & 5.8 & 101 & 0.74 & 4.1 & 5.8 \\
\hline
\end{tabular}


Using LNGS model $\square$ Using RGS model
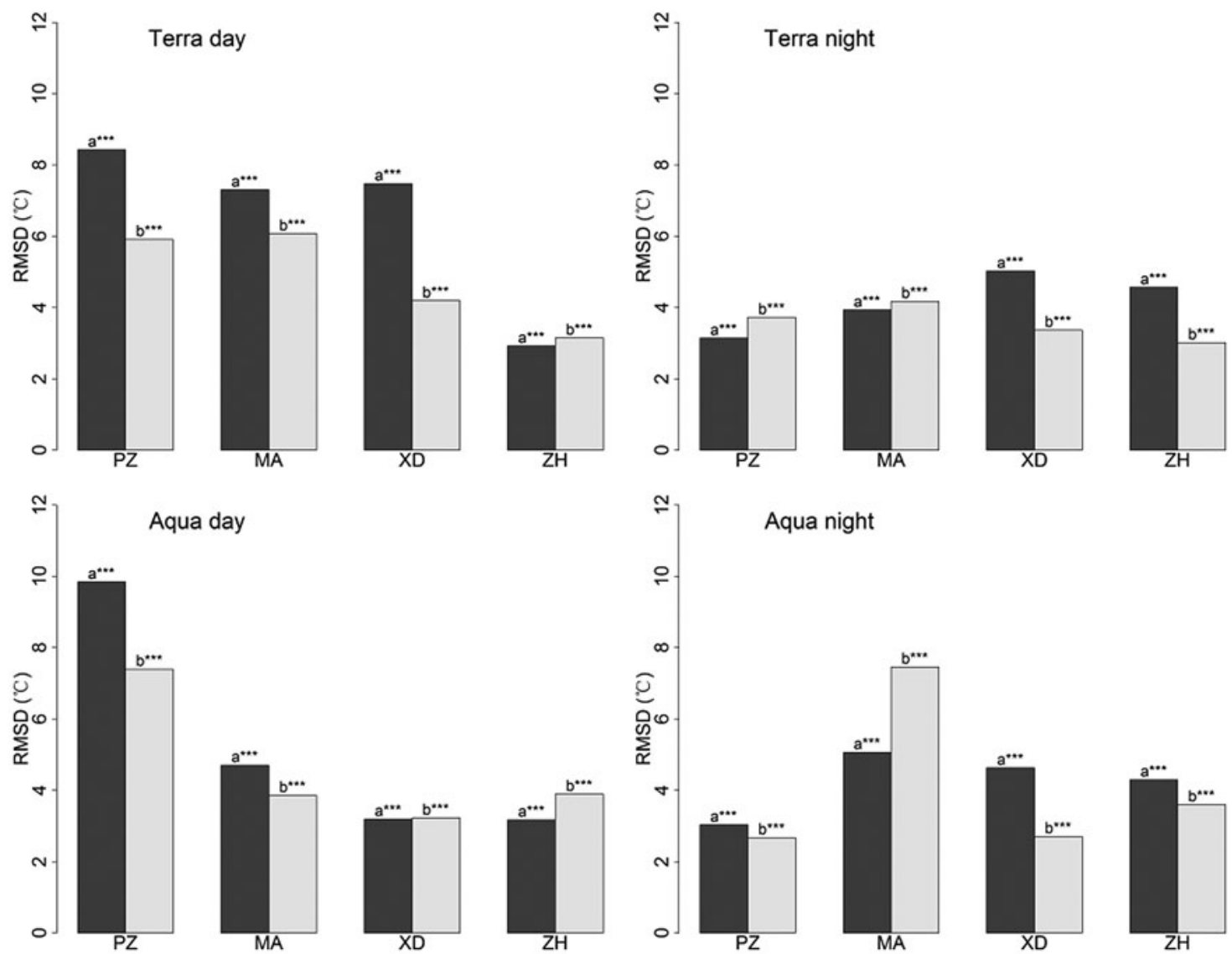

Fig. 4. Comparison between the LNGS and RGS models for $T_{\text {mean }}$ estimation. 'PZ', Parlung Zangbo; 'MA', Muztagh Ata; 'XD', Xiao Dongkemadi; ' $\mathrm{ZH}$ ', Zhadang. Asterisks indicate the significance of the differences: *** indicates 0.001 significance level; ${ }^{* *}$ indicates 0.01 significance level; * indicates 0.05 significance level; letters without asterisks indicate insignificant differences.

(Fig. 9), which is consistent with $T_{\text {mean }}$ and $T_{\min }$. The averaged RMSD of $5.9^{\circ} \mathrm{C}$ for the TLR method is comparable with $5.3^{\circ} \mathrm{C}$ for the RGS model using MODIS LST. The RGS model based on MODIS night-time LST showed relatively better performance with an averaged RMSD of $4.5^{\circ} \mathrm{C}$, whereas the accuracies are remarkably lower than those of $T_{\text {mean }}$ and $T_{\text {min }}$ estimation. As shown in Figure S4, a fair comparison based on days with four daily MODIS observations indicated that the RGS model based on MODIS night-time LST, with a mean RMSD of $4.8^{\circ} \mathrm{C}$, is superior to that based on MODIS daytime LST, with a mean RMSD of $5.7^{\circ} \mathrm{C}$ for $T_{\max }$ estimation. The RGS model based on MODIS/Aqua night-time LST with a mean RMSD of $4.5^{\circ} \mathrm{C}$ performed the best.

\section{DISCUSSION}

\subsection{Limitations of MODIS LST on glacier surfaces of the TP}

\subsubsection{MODIS night-time LST}

A clear cold bias frequently occurs at night for MODIS LST. This was particularly true for MODIS/Aqua night-time LST at the Parlung Zangbo, resulting in the maximum error among all four MODIS night-time LST terms (Table 2). This can be largely explained by deficiencies in the MODIS night-time cloud-detecting algorithm (Ackerman and others, 1998). A relatively large proportion of undetected clouds exists in MODIS night-time LST (Østby and others, 2014; Zhang and others, 2016b). When undetected cloud pixels exist, cloud top temperatures will take the place of true LSTs, resulting in much lower values. A cold bias of more than $10^{\circ} \mathrm{C}$ existed in up to 38 cases of MODIS nighttime LST observed at the Parlung Zangbo. Such large errors resulted from undetected clouds have also been observed in other regions (Langer and others, 2010; Westermann and others, 2011, 2012).

\subsubsection{MODIS daytime $L S T$}

During the daytime, obvious warm bias existed for many cases, and almost throughout the year for Aqua daytime LST observed at Parlung Zangbo, which resulted in extremely large errors (Fig. 3). This result can be partly explained by the possible failure in atmospheric correction, as indicated by Østby and others (2014). It should be noted that MODIS daytime LST is also affected by undetected clouds (Williamson and others, 2013), although such influence is significantly smaller than for MODIS night-time LST (Ackerman and others, 1998; Zhang and others, 2016b). Hall and others (2008b) also discussed other possible reasons such as the mixed-pixel effect of melting water ponds within the pixel. However, this factor was less likely to be the dominant factors in the present study. Figure 10 plots the heterogeneity of MODIS pixel used. The variability of altitudes within pixels of the Xiao Dongkemadi and the Parlung Zangbo stations was small with standard errors 
Using TLR
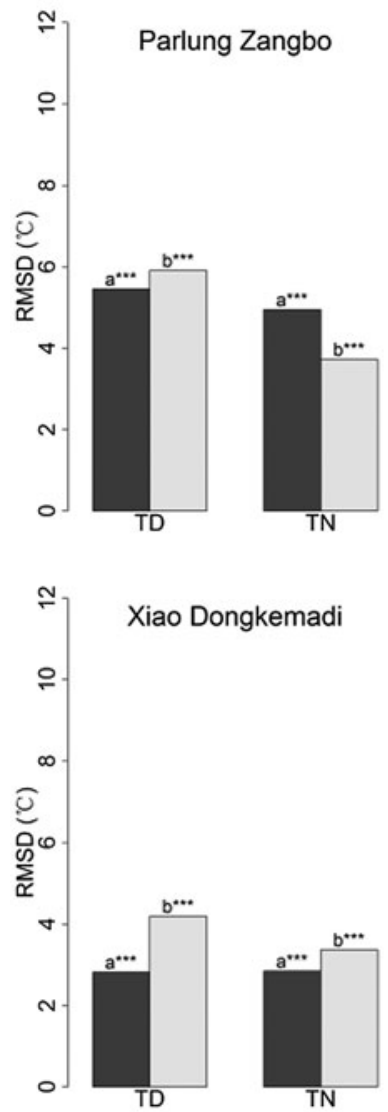
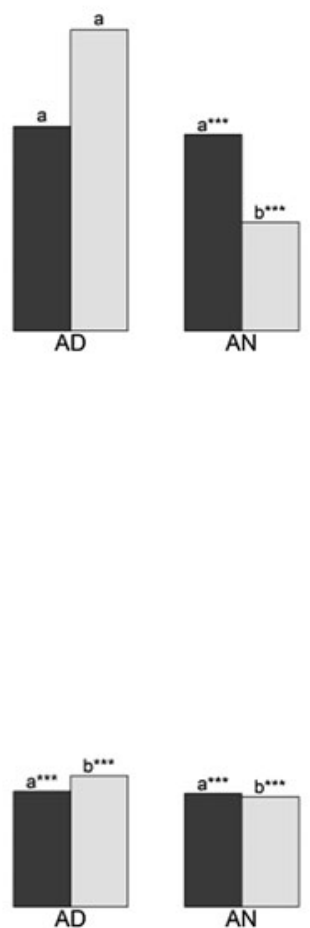

Using RGS model based on MODIS LST
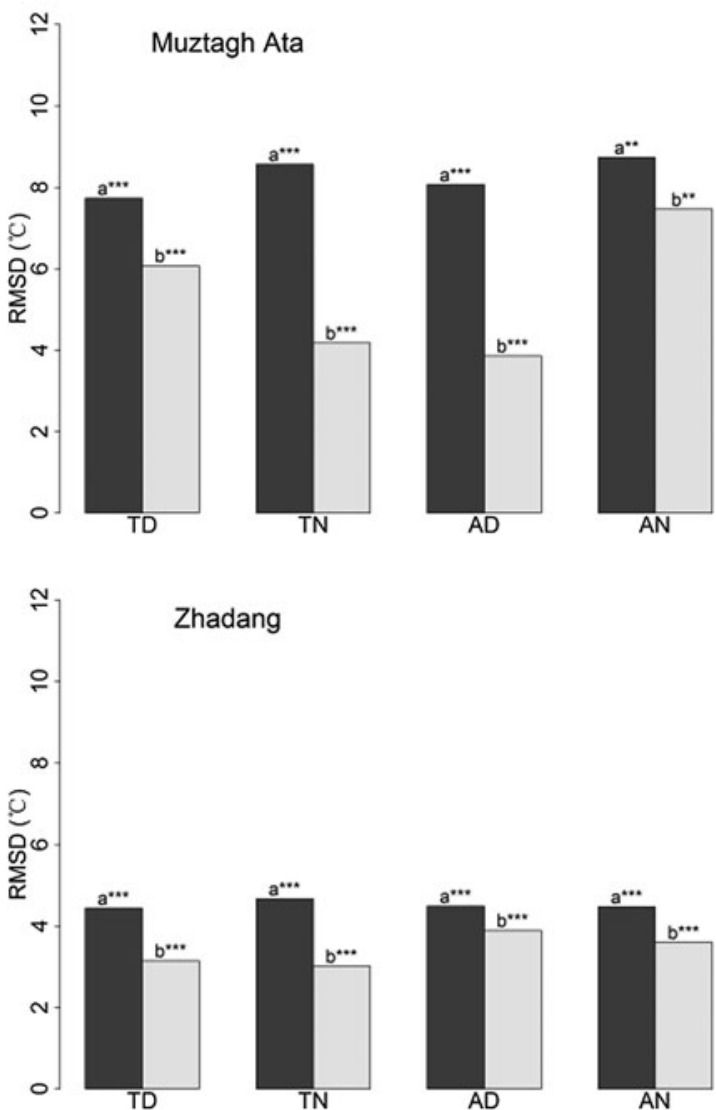

Fig. 5. Comparison between the TLR method and the RGS model based on MODIS LST for $T_{\text {mean }}$ estimation. 'TD', Terra Day; 'TN', Terra Night; 'AD', Aqua Day; 'AN', Aqua Night. Asterisks indicate the significance of the differences: *** indicates 0.001 significance level; $* *$ indicates 0.01 significance level; * indicates 0.05 significance level; letters without asterisks indicate insignificant differences.

of only 75 and $63 \mathrm{~m}$, respectively. However, a relatively large proportion of non-glacier areas was covered within both MODIS pixels with fractions of 28 and $32 \%$ for Xiao Dongkemadi and Parlung Zangbo, respectively. During the day, LST is generally higher than $T_{\text {air, }}$ whereas LST on glacier surfaces cannot exceed the melting point (e.g. $\left.0^{\circ} \mathrm{C}\right)\left(\right.$ Hall and others, 2006) even when $T_{\text {air }}$ is above $0^{\circ} \mathrm{C}$. Thus, daytime enhances the strong LST difference between glacier and non-glacier area within MODIS pixels, especially in warm seasons. Similarly, obvious temperature differences of $>10^{\circ} \mathrm{C}$ are observed between snow and snow-free surfaces in summer over a high-arctic tundra (Westermann and others, 2011). Therefore, the warm-bias errors for our study may be largely attributed to pixel heterogeneity.

\subsubsection{Comparison with other evaluation or validation studies}

Previous validation over the TP has focused mainly on areas with vegetated land cover. Yu and Ma (2011) obtained RMSD values of $3.1-5.3^{\circ} \mathrm{C}$ across three test sites with different land cover types (farm land, forest and desert grassland) in the northeastern TP. Min and others (2015) found a general RMSD of $5.3^{\circ} \mathrm{C}$ at an alpine meadow-dominated station in the eastern TP. Wang and Min (2014) obtained an RMSD of $2.2^{\circ} \mathrm{C}$ for MODIS night-time LST observed at the Linzhi area in the southeastern TP. All of these studies included problems of pixel heterogeneity to varying degrees. However, our study featured obviously higher errors in MODIS daytime LST owing to the strong contrast between glacier and non-glacier area within MODIS pixels, especially at Parlung Zangbo.

Compared with validation studies for glacier/ice surfaces in the Arctic (Østby and others, 2014) and Greenland (Hall and others, 2008a, Koenig and Hall, 2010) areas, where ice surfaces are relatively homogeneous, an obviously larger warm bias for MODIS daytime LST was found in this study owing to the strong pixel heterogeneity. In the TP, glaciers are generally small $\left(<1 \mathrm{~km}^{2}\right)$ (Guo and others, 2014). The mixed-pixel problem is a known limitation in MODIS LST observation; downscaling is needed for future studies on glacier surfaces of the TP using MODIS LST.

Despite the larger RMSDs for MODIS daytime LST than those reported in previous studies (Wan and others, 2002; Coll and others, 2005), the evaluation results of MODIS night-time LST are generally consistent with them (Bosilovich, 2006; Wang and others, 2008; Wang and Liang, 2009; Li and others, 2014; Krishnan and others, 2015). The minimum RMSDs of the Xiao Dongkemadi and the Parlung Zangbo stations were only 2.3 and $4.3^{\circ} \mathrm{C}$, respectively, which is within the range of $2.2-4.6^{\circ} \mathrm{C}$ observed for MODIS night-time LST over the TP (Yu and Ma, 2011; Wang and Min, 2014; Min and others, 2015). The night-time LST could be more homogeneous within the pixels due to the absence of large uncertainty introduced by solar radiation at daytime (Wang and others, 2008; Yu and Ma, 2011). 
Using LNGS model $\square$ Using RGS model
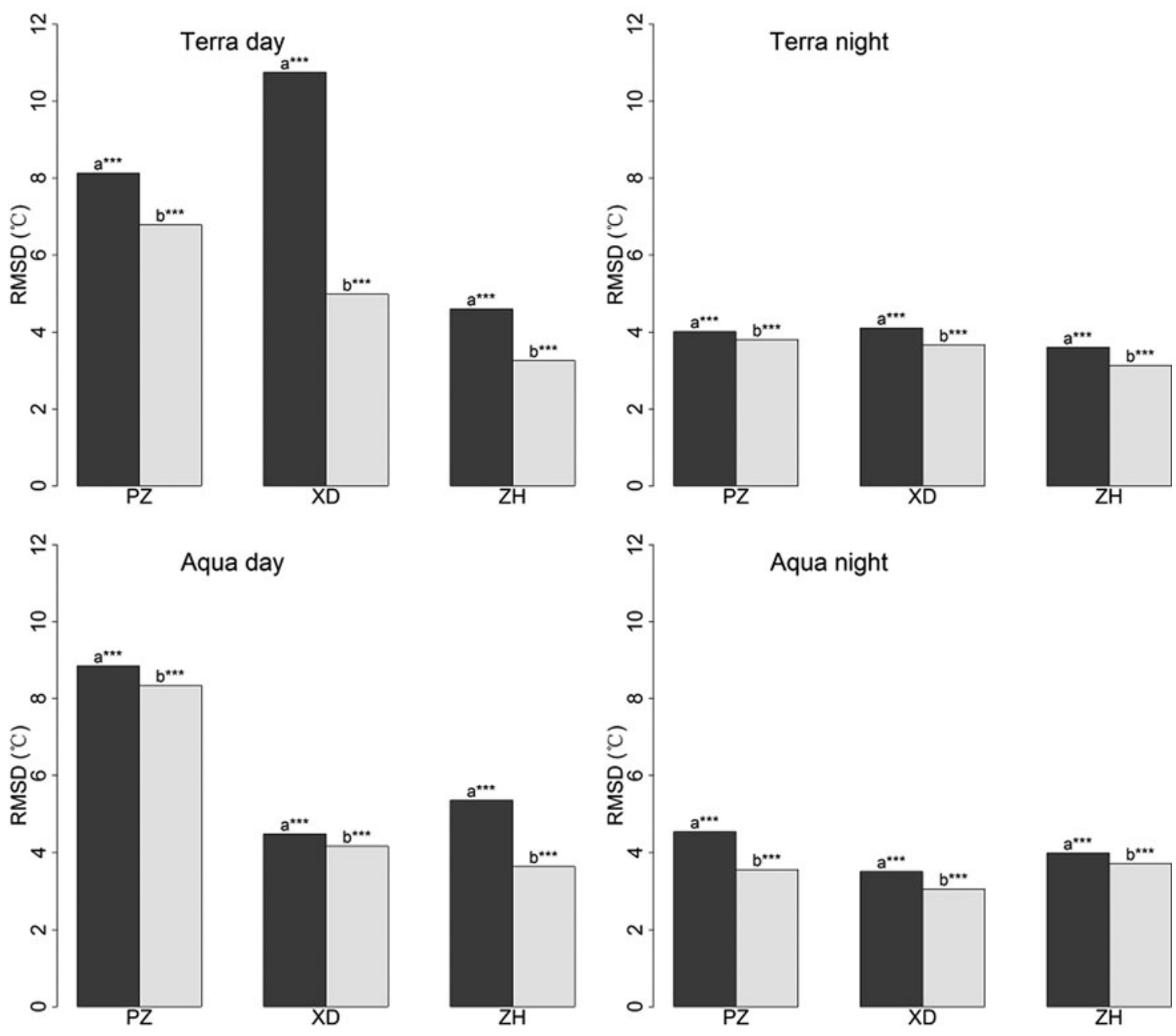

Fig. 6. Comparison between the LNGS and RGS models for $T_{\min }$ estimation. 'PZ', Parlung Zangbo; 'XD', Xiao Dongkemadi; 'ZH', Zhadang. Asterisks indicate the significance of the differences: *** indicates 0.001 significance level; ** indicates 0.01 significance level; * indicates 0.05 significance level; letters without asterisks indicate insignificant differences.

\subsubsection{Data quality}

To further evaluate the effects of MODIS-claimed QC flags, the evaluation excluding low-quality data (i.e. QC > 1) was also examined (Table 2). Except for the clear improvement for Terra night-time LST observed at Xiao Dongkemadi, generally comparable accuracies or limited improvements can be obtained after removing the suspicious data. This indicates the dominating effect of pixel heterogeneity for MODIS daytime LST and also reveals the fact that undetected clouds may still exist after removing the low-quality data. It should be noted that removing the suspicious data can largely reduce the available sample amounts.

\subsection{Comparison between the RGS and LNGS models}

The RGS models showed consistently higher accuracies than the LNGS models for estimations of $T_{\text {mean }}, T_{\min }$ and $T_{\max }$ (Figs $4,6,8)$. This indicates that there may be strong differences of $T_{\text {air }}-$ LST relationship between glacier and non-glacier surfaces, and RGS models should be used on glacier surfaces. It should be noted that the LNGS model was trained using samples from non-glacier stations and validated using observations from glacier stations. Due to the large variation of elevation among non-glacier stations, we also tried to add the elevation information to LNGS model to test if it could get higher accuracies, and such LNGS models are built as:

$$
T_{\text {air }}=a+b \times \mathrm{LST}+c \times Z,
$$

where LST is MODIS LST data including four instantaneous observations as mentioned before; $Z$ is elevation; $a, b$ and $c$ are all regression coefficients. However, after adding the factor of elevation, the LNGS models produced even lower accuracies (Fig. S5). This may be because the temperature variation with altitude is discontinuous between glacierand non-glacier surfaces (Wang and others, 2013a); thus, such effects derived from non-glacier observations may be strongly biased for glacierized areas and lead to more errors.

Figure 11 shows the regression models between $T_{\text {air }}$ of AWSs and MODIS LST at four pass times at different glaciers. For each MODIS pass time, differences were noted among models of the four glaciers, which indicates that different models may need to be built for obtaining locally accurate estimations on glacier surfaces. However, obtaining sufficient $T_{\text {air }}$ observations on individual glacier surface is extremely difficult. In addition, the performances of fixed models, especially those based on Terra night-time LST, built at a given glacier AWS shows highly acceptable validation results at the other glaciers (Figs 5, 7, 9). This indicates 


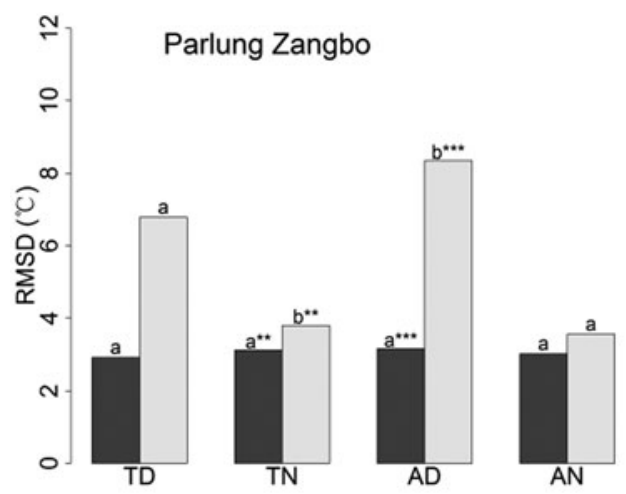

Using TLR

Using RGS model using MODIS LST
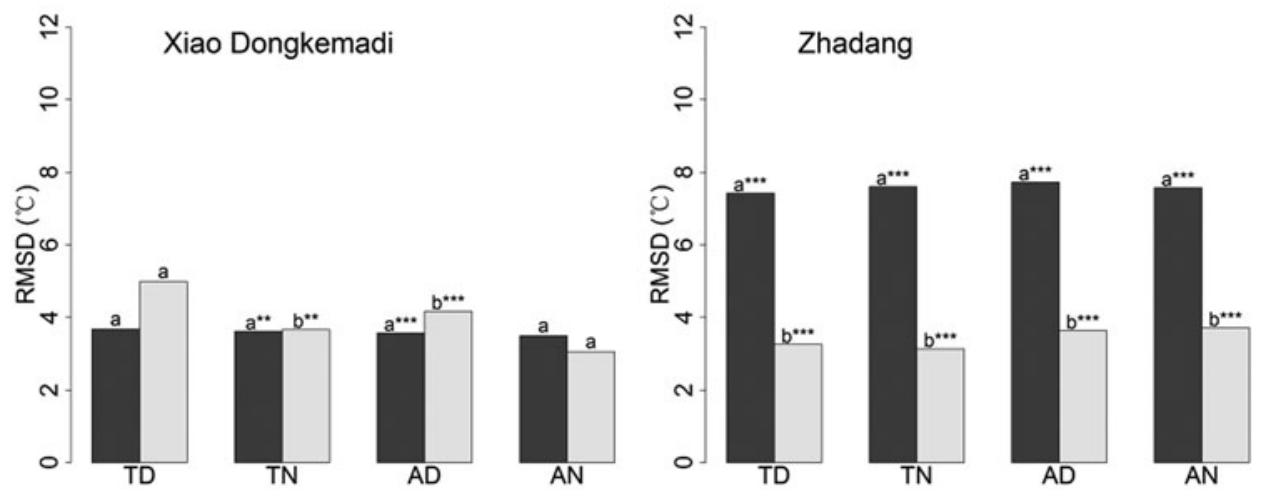

Fig. 7. Comparison between the TLR method and the RGS model based on MODIS LST for $T_{\min }$ estimation. 'TD', Terra Day; 'TN', Terra Night; 'AD', Aqua Day; 'AN', Aqua Night. Asterisks indicate the significance of the differences: *** indicates 0.001 significance level; ** indicates 0.01 significance level; ${ }^{*}$ indicates 0.05 significance level; letters without asterisks indicate insignificant differences.

- Using LNGS model $\square$ Using RGS model
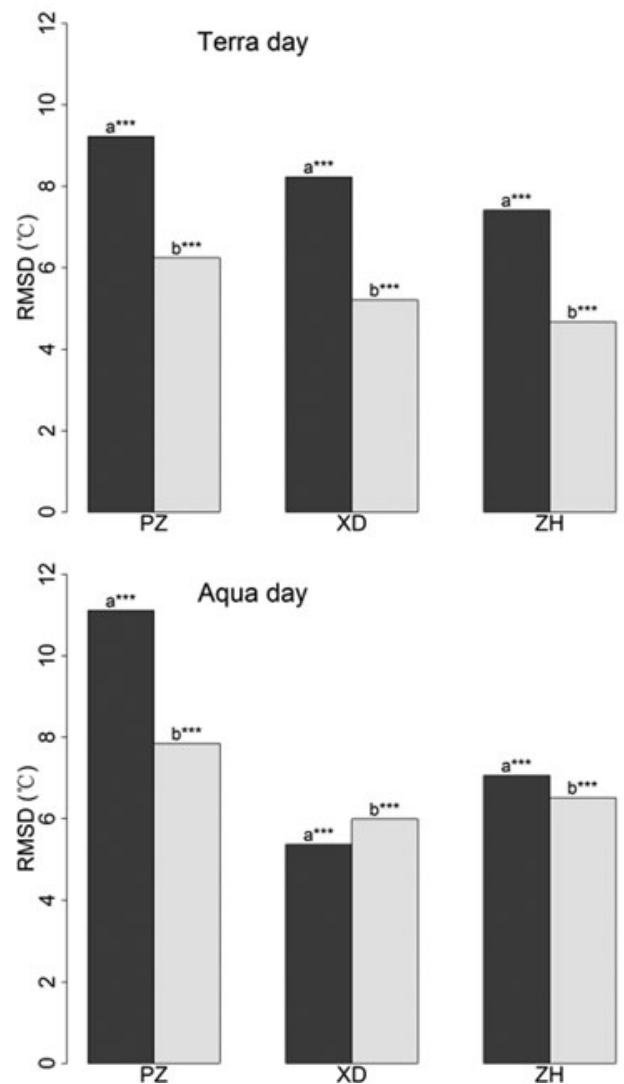
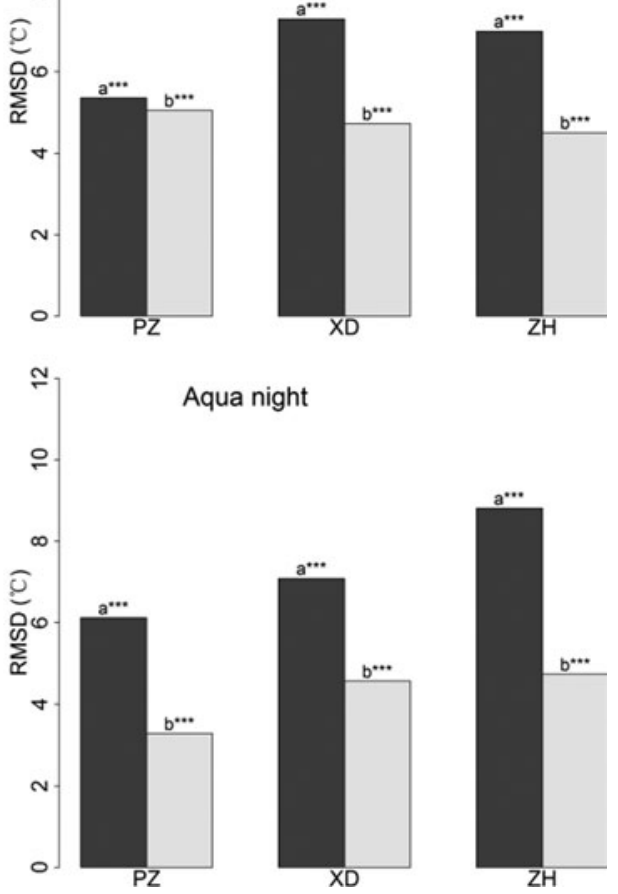

qua night
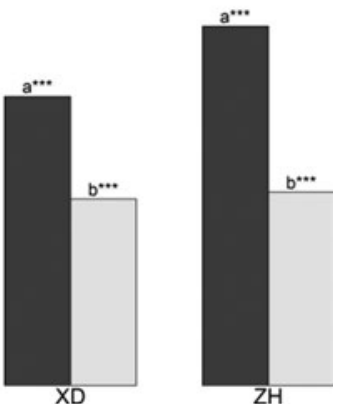

Fig. 8. Comparison between the LNGS and RGS models for $T_{\max }$ estimation. 'PZ', Parlung Zangbo; 'XD', Xiao Dongkemadi; 'ZH', Zhadang. Asterisks indicate the significance of the differences: $* * *$ indicates 0.001 significance level; ${ }^{* *}$ indicates 0.01 significance level; $*$ indicates 0.05 significance level; letters without asterisks indicate insignificant differences. 


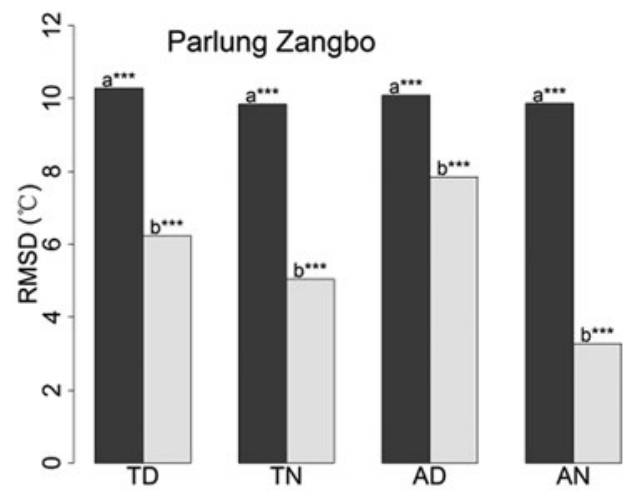

Using TLR

Using RGS model using MODIS LST
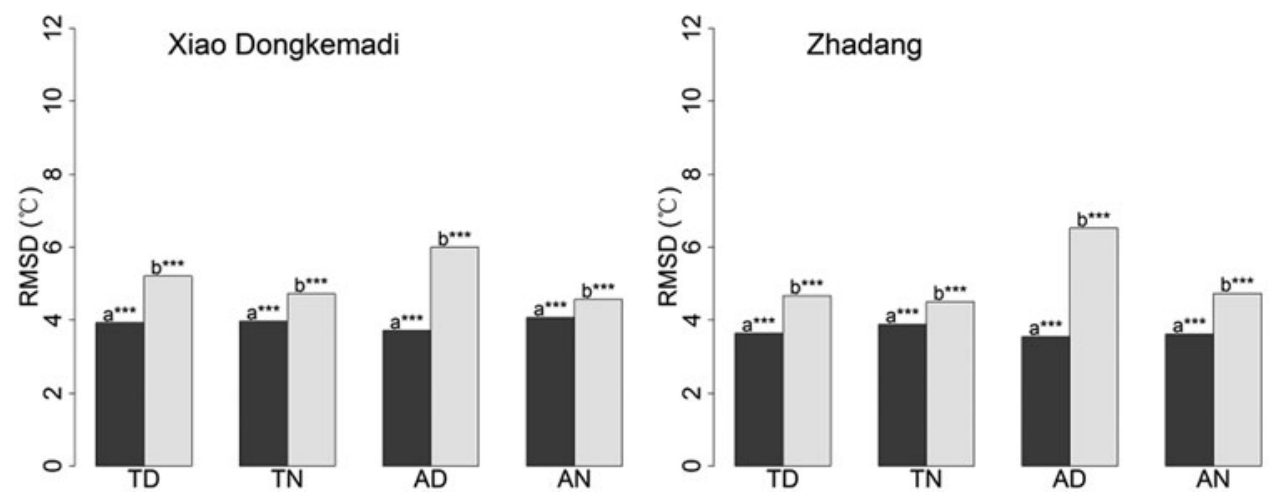

Fig. 9. Comparison between the TLR method and the RGS model based on MODIS LST for $T_{\max }$ estimation. 'TD', Terra Day; 'TN', Terra Night; 'AD', Aqua Day; 'AN', Aqua Night. Asterisks indicate the significance of the differences: *** indicates 0.001 significance level; ${ }^{* *}$ indicates 0.01 significance level; * indicates 0.05 significance level; letters without asterisks indicate insignificant differences.

that the $T_{\text {air }}$-LST relationship may not vary greatly among different glacier sites and the RGS models are recommended for $T_{\text {air }}$ estimation.

\subsection{Implications, uncertainties and future developments for $T_{\text {air }}$ estimation using MODIS LST in glacierized areas over the TP}

Both MODIS daytime and night-time LST have shown relatively good performances in $T_{\text {air }}$ estimation in many mountainous areas around the world including the TP (Zhang and others, 2011, 2016a, Benali and others, 2012). Problems such as obvious warm bias were identified with MODIS daytime LST in glacierized areas as shown in this study. We attribute its evident deficiency to the mixedpixel problem resulting from strong temperature heterogeneity in the daytime. This problem affects the performance of MODIS daytime LST in $T_{\text {air }}$ estimation. However, MODIS night-time LST showed much lower bias than MODIS daytime LST in glacierized regions. Thus, MODIS
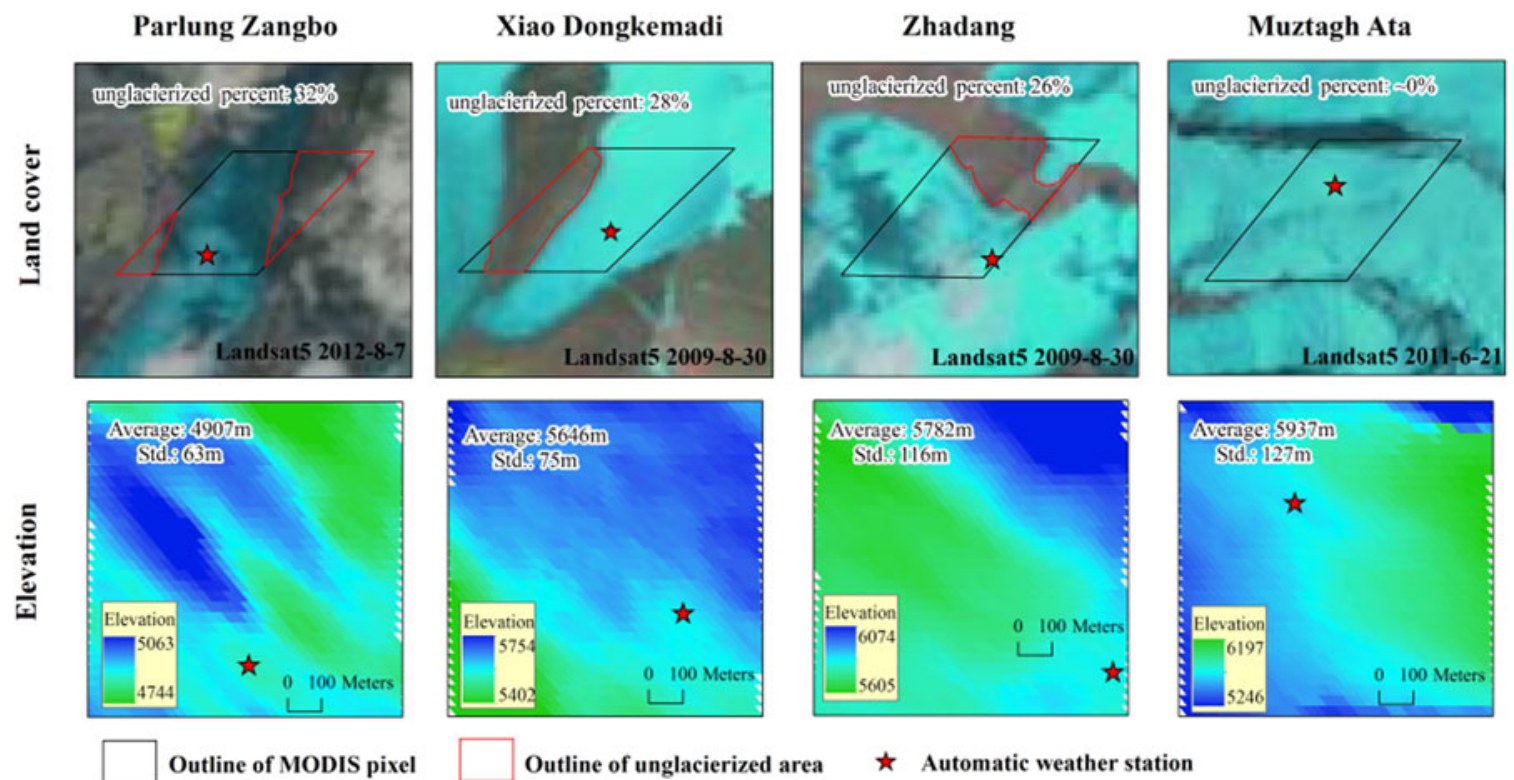

Outline of unglacierized area

$\star$ Automatic weather station

Fig. 10. Distribution of land covers and elevations within MODIS pixels at four glacier AWSs. Land covers (upper) are described by Landsat images observed during the time period of data used in this study. Elevation (lower) information within MODIS pixels are drawn from ASTER GDEM dataset (http://gdem.ersdac.jspacesystems.or.jp/). 


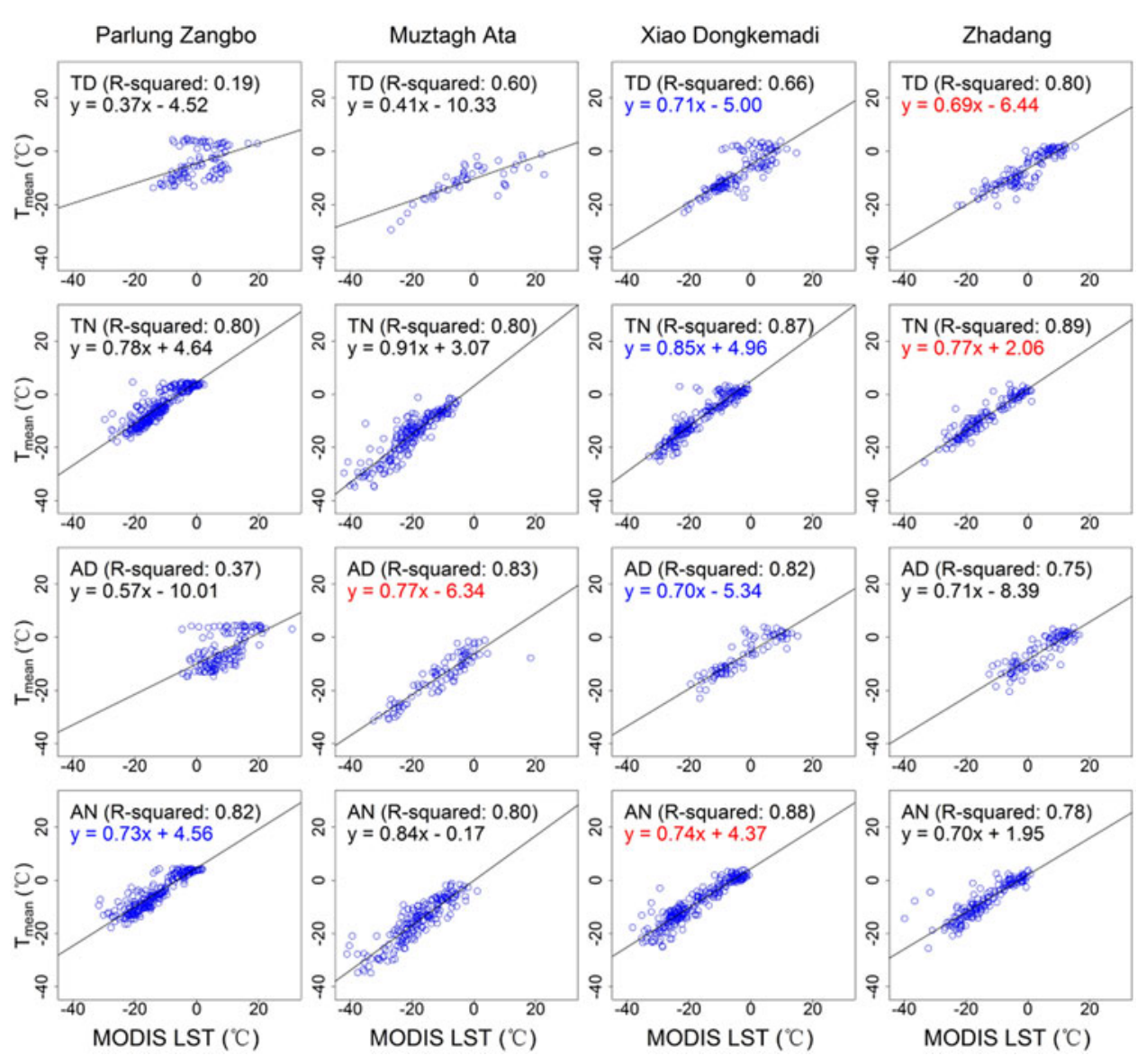

Fig. 11. Linear regression between $T_{\text {mean }}$ and MODIS LST at four glacier AWSs. The coefficients of determination $\left(R^{2}\right)$ and equations are shown at top-left in each sub-plot. Equations in red colors indicate the best models and those in blue colors indicate the second-best models for different MODIS pass times. 'TD', Terra Day; 'TN', Terra Night; 'AD', Aqua Day; 'AN', Aqua Night.

night-time LST are strongly recommended in glacierized areas of the TP.

Terra night-time LST appeared to be more reliable than Aqua night-time LST illustrated by the higher accuracies in $T_{\text {air }}$ estimation (Fu and others, 2011; Zhang and others, 2011). Generally lower bias of Terra LST than Aqua LST was found in this study (Section 4.1) and other validation studies of the TP (Yu and Ma, 2011; Min and others, 2015). Thus, the RGS models based on Terra night-time LST are recommended for $T_{\text {air }}$ estimation (Figs 11, S6 and S7).

Our study indicates that the best accuracies of $T_{\text {mean }}$ and $T_{\text {min }}$ estimation using MODIS LST, with RMSDs of 3.0 and $2.9^{\circ} \mathrm{C}$, respectively, are clearly higher than that of $T_{\max }$ estimation, with an RMSD of $4.5^{\circ} \mathrm{C}$. This result is consistent with those reported in other studies (Benali and others, 2012; Good, 2015); however, the reported performance differences at $\sim 1.5^{\circ} \mathrm{C}$ are larger and the accuracies of $T_{\max }$ estimation are obviously lower than those in other regions (Zhang and others, 2011; Xu and others, 2014; Oyler and others, 2016). $T_{\max }$ occurs during the day; therefore, clouds can greatly affect the accuracies of MODIS LST (Williamson and others, 2013) as well as the $T_{\text {air }}$-LST relationship (Zhang and others, 2016b). In addition, the lower accuracy of $T_{\max }$ estimation can be largely attributed to the strong influence of pixel heterogeneity on daytime LST. Future studies may need to develop advanced downscale methods for obtaining more accurate and fine LST data on glacier surfaces. It should be noted that compared with this study, a much larger RMSD was found for air temperature estimation from MODIS LST in the Antarctic (Meyer and others, 2016) where ice sheets are widespread, which may be largely due to: (1) Antarctic area has more extremely low temperatures $\left(<-35^{\circ} \mathrm{C}\right)$ which are hard to predict (Meyer and others, 2016); (2) the accuracies reported from their study are actually for instaneous air temperatures, whereas those from this study focus on daily air temperatures.

Undetected clouds present in MODIS night-time LST have obviously negative effects on $T_{\text {air }}$ estimation (Zhang and others, 2016b). The estimation accuracies using MODIS LST can be greatly improved by screening samples (Zhang and others, 2016b). In addition, removing suspicious data based on MODIS claimed QC flags can also contribute to more accurate estimation (Williamson and others, 2013; Zhang and others, 2016a). This option was not used in the present study owing to limited $T_{\text {air }}$ observations from glacier AWSs. Future study is needed to obtain additional ground measurements at glacier surfaces and to build more reliable and accurate models for glacierized regions. In addition to LST, other variables including latitude, longitude, elevation, Julian day and solar zenith have been used in several studies to improve the estimation accuracies (Benali and others, 2012; Xu and others, 2012; Janatian and others, 2016; Zhang and others, 2016a). Owing to the relatively short time series of $T_{\text {air }}$ observations and the limited number of stations, some variables including latitude, longitude and elevation were not used in this study. The Julian day was tested as an auxiliary variable and only slight improvements were achieved with the RMSD decrease of $<0.01^{\circ} \mathrm{C}$. 


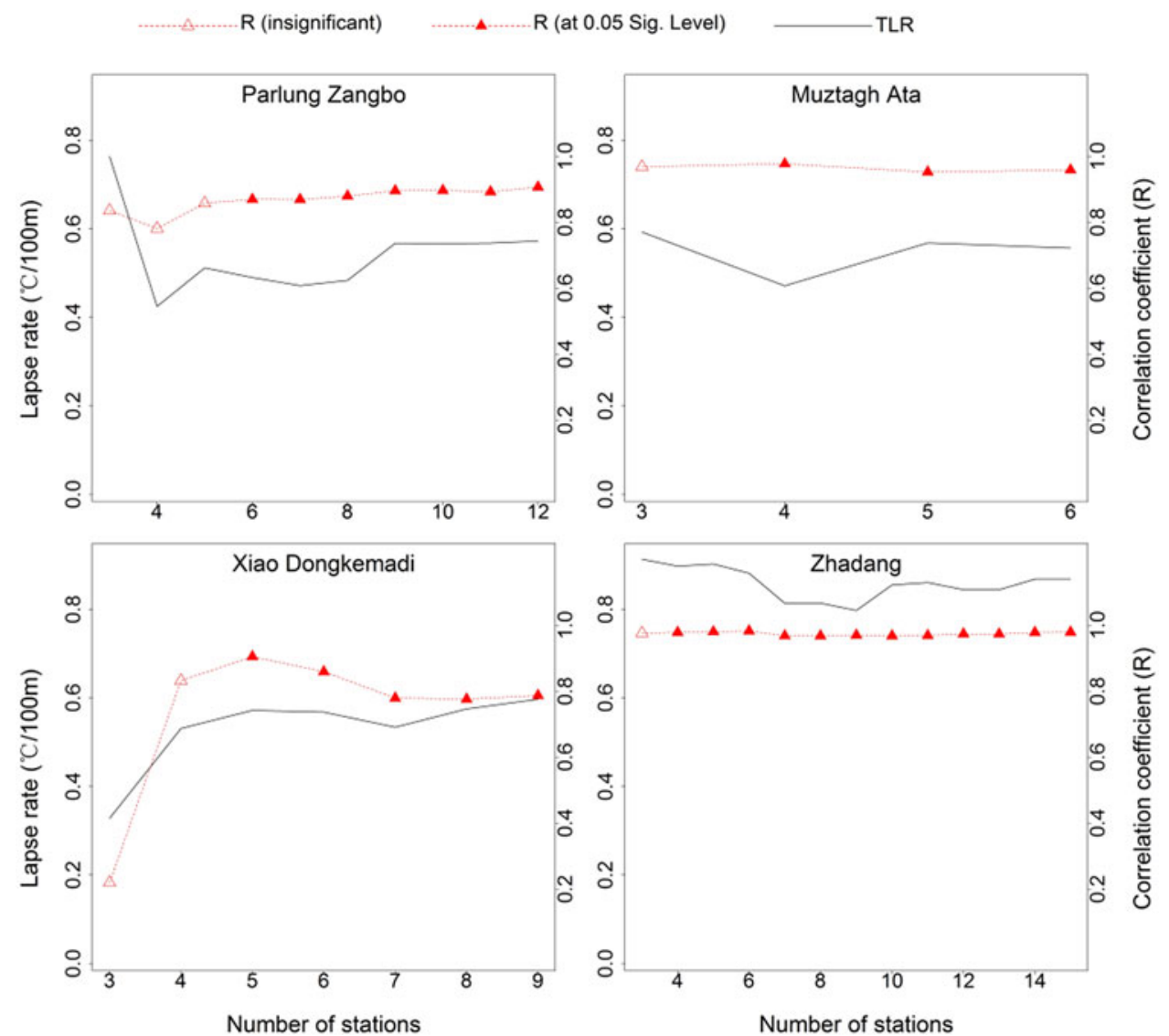

Fig. 12. Sensitivity tests on number of stations for estimating TLR of $T_{\text {mean }}$.

Future research may benefit from including more efficient auxiliary variables.

\subsection{MODIS LST vs TLR for $T_{\text {air }}$ estimation in glacierized basins}

\subsubsection{Uncertainty of $T L R$}

TLR is often assumed to have a constant value of $\sim 0.65^{\circ} \mathrm{C} /$ $100 \mathrm{~m}$ in glacierized regions (Hock and Holmgren, 2005; Arnold and others, 2006; Machguth and others, 2006). However, several studies have reported that TLR is not a spatial or temporal constant owing to variability in the microclimatic conditions (Rolland, 2003; Li and others, 2013a). In this study, the spatial representativeness of TLR was considered through sensitivity tests. Figure 12 shows that the TLR of $T_{\text {mean }}$ can vary substantially depending on the number of neighboring stations. When the number is small, only insignificant lapse rates and relatively weak $R$ can be obtained. A high correlation coefficient of $\sim 0.8$ between $T_{\text {air }}$ and elevation appeared when station number was big enough; however, TLR still changed with a relatively large variation as the station number kept increasing. The first value of station number that passed the 0.05 significance test was chosen (Fig. 12); and these values are 6 for the Parlung Zangbo, 5 for the Xiao Dongkemadi, 4 for the Zhadang and 4 for the Muztagh Ata stations, respectively. We also conducted the sensitivity tests for $T_{\min }$ and $T_{\max }$ and achieved similar results. Finally, for each AWS, the annual mean air temperature shows generally good negative correlation with elevation among the neighboring stations selected (Fig. 2b). The temporal variation of TLR was also analyzed in this study. Monthly TLR was selected because it generally has higher accuracy than daily TLR. In this study for $T_{\text {mean }}$ interpolation, the averaged RMSE produced using monthly $\operatorname{TLR}\left(5.2^{\circ} \mathrm{C}\right)$ was found to be smaller than that using daily $\operatorname{TLR}\left(5.9^{\circ} \mathrm{C}\right)$. This may be because fluctuations in microclimates may affect the general pattern of TLR.

TLR can be affected by microclimatic conditions such as terrains, humid conditions and valley winds in various mountainous regions around the world (Rolland, 2003; Minder and others, 2010), including the TP (Li and Xie, 2006; Kattel and others, 2013; Liu and others, 2013). In particular, the temperature inversion in high-altitude or glacierized regions adds more complexity (Nilsson, 2009; Li and others, 2013a). Strong differences between the TLRs of low- and high-altitude regions have also been reported in the TP (Liu and others, 2013). Limited high-altitude stations may introduce large errors (Immerzeel and others, 2014). The TLR at the glacier surface may be clearly different from that in non-glacierized regions (Nilsson, 2009). Our study confirmed that large estimation errors can be introduced at the glacier surface over the TP based on TLR derived from lowaltitude stations.

\subsubsection{Implications for selection of $\mathrm{T}_{\text {air }}$ estimation from TLR or MODIS LST in glacierized areas}

Both TLR (Stahl and others, 2006; Zhang and others, 2015) and MODIS LST (Benali and others, 2012; Zhang and others, 2016a) have shown good performance in $T_{\text {air }}$ estimation in mountainous areas. In glacierized areas, MODIS/Terra night-time LST showed highly acceptable performances in $T_{\text {air }}$ ( $T_{\text {mean }}$ and $T_{\text {min }}$ ) estimation, which were generally better than TLR in most cases as shown in the present study. 
The most evident deficiency of MODIS LST is the missing data owing to cloud blockage (Yu and others, 2016; Zhang and others, 2016a; Zhu and others, 2017). Interpolation for MODIS LST may introduce more uncertainties although some advanced methods have been developed ( $\mathrm{Xu}$ and Shen, 2013; Yu and others, 2014). In addition, the problems of undetected clouds, data quality and mixed pixels may also introduce errors. The TLR based on meteorological stations in glacierized areas may generate more accurate $T_{\text {air }}$ estimation. However, MODIS LST is strongly recommended for $T_{\text {air }}$ estimation in glacierized areas where stations are sparse.

It should be noted that this study is not intended to negate the importance of TLR; we also tested performance for stations located in non-glacierized regions. The TLR method showed comparable performance in $T_{\text {air }}$ estimation compared with that using MODIS LST (Fig. S8). This indicates that if station networks are sufficiently dense and the produced TLR is locally reliable, TLR is an efficient method and is highly recommended because of its simple concept and ease of use. However, MODIS LST can be a good alternative for more accurate $T_{\text {air }}$ estimation in glacierized basins where high-altitude stations are too scarce to generate locally reliable TLR.

\section{CONCLUSION}

In this study, MODIS LST data were used for $T_{\text {air }}\left(T_{\text {mean }}, T_{\text {min }}\right.$ and $\left.T_{\max }\right)$ estimations. The performances were evaluated by comparing with actual $T_{\text {air }}$ observations as well as with the results produced by the TLR method. Since careful validation is the basis of efficient application of remotely sensed LST, MODIS LST data were first compared with in-situ LST measurements of AWSs at two glaciers. The comparison results indicated that MODIS daytime LST data may have large errors (with mean RMSD of $8.0^{\circ} \mathrm{C}$ ) on glacier surfaces of the TP likely owing to the mixed-pixel problem. In comparison, MODIS night-time LST (with mean RMSD of $4.0^{\circ} \mathrm{C}$ ), especially MODIS/Terra night-time LST (with mean RMSD of $3.3^{\circ} \mathrm{C}$ ), shows much lower bias. It was found that the selected regression models built at the RGS for the estimation of $T_{\text {air }}$ showed higher accuracy than those at LNGS. The performances of the RGS models based on MODIS nighttime LST with mean RMSDs of $3.3,3.0$ and $4.8^{\circ} \mathrm{C}$, were all obviously better than those of the RGS models based on MODIS daytime LST with mean RMSDs of 4.2, 4.7 and $5.7^{\circ} \mathrm{C}$ for the estimations of $T_{\text {mean }} T_{\text {min }}$ and $T_{\max }$ on glacier surfaces of the TP, respectively. The accuracies of $T_{\text {mean }}$ and $T_{\min }$ estimations were significantly higher than those of $T_{\max }$ estimation using MODIS LST. Compared with the TLR method (with mean RMSDs of $5.2,4.7$ and $5.9^{\circ} \mathrm{C}$ for $T_{\text {mean }}$ $T_{\min }$ and $T_{\max }$ estimations, respectively), the RGS models based on MODIS night-time LST produced better accuracies. Thus, regression using MODIS night-time LST can be a good alternative method for TLR for more accurate $T_{\text {air }}$ estimation in glacierized areas in the TP.

\section{SUPPLEMENTARY MATERIAL}

The supplementary material for this article can be found at https://doi.org/10.1017/jog.2018.6.

\section{ACKNOWLEDGEMENTS}

This study was supported by the National Natural Science Foundation of China (grant No. 41371087 and 41701079), and the China Postdoctoral Science Foundation (grant No. 2017M611013). We thank the Tanggula Station for Cryosphere Environment Observation and Research (supported by the National Natural Science Foundation of China grant No. 41271079 and 41130638), the Southeast Tibetan Plateau Station for Integrated Observation and Research of Alpine Environment, the Muztagh Ata Station for Westerly Environment Observation and Research and the Nam Co Station for Multisphere Observation and Research for providing ground measurements of longwave radiation and air temperature data. In addition, we are grateful to the Chinese Meteorology Administration (http://data. cma.cn/) for providing air temperature data. The MODIS LST products can be downloaded at no charge from the Reverb website (http://reverb.echo.nasa.gov/).

\section{REFERENCES}

Ackerman SA and 5 others (1998) Discriminating clear sky from clouds with MODIS. J. Geophys. Res. Atmos., 103(D24), 32141-32157

Arnold NS, Rees WG, Hodson AJ and Kohler J (2006) Topographic controls on the surface energy balance of a high Arctic valley glacier. J. Geophys. Res. Earth Surf., 111(F2)

Benali A, Carvalho AC, Nunes JP, Carvalhais N and Santos A (2012) Estimating air surface temperature in Portugal using MODIS LST data. Remote Sens. Environ., 124, 108-121

Bisht G, Venturini V, Islam S and Jiang L (2005) Estimation of the net radiation using MODIS (Moderate Resolution Imaging Spectroradiometer) data for clear sky days. Remote Sens. Environ., 97(1), 52-67

Bosilovich MG (2006) A comparison of MODIS land surface temperature with in situ observations. Geophys. Res. Lett., 33(20), 1063-1075

Cai D, You Q, Fraedrich K and Guan Y (2017) Spatiotemporal temperature variability over the Tibetan Plateau: altitudinal dependence associated with the global warming hiatus. J. Clim., 30(3), 969-984

Caidong C and Sorteberg A (2010) Modelled mass balance of Xibu glacier, Tibetan Plateau: sensitivity to climate change. J. Glaciol., 56(196), 235-248

Coll C and 6 others (2005) Ground measurements for the validation of land surface temperatures derived from AATSR and MODIS data. Remote Sens. Environ., 97(3), 288-300

Craney TA and Surles JG (2002) Model-dependent variance inflation factor cutoff values. Qual. Eng., 14(3), 391-403

Emamifar S, Rahimikhoob A and Noroozi AA (2013) Daily mean air temperature estimation from MODIS land surface temperature products based on M5 model tree. Int. J. Climatol., 33(15), 3174-3181

Fu G and 5 others (2011) Estimating air temperature of an alpine meadow on the Northern Tibetan Plateau using MODIS land surface temperature. Acta Ecol. Sin., 31(1), 8-13

Gao H, HeX, Ye B and PuJ (2012) Modeling the runoff and glacier mass balance in a small watershed on the Central Tibetan Plateau, China, from 1955 to 2008. Hydrol. Process., 26(11), 1593-1603

Gao TG and 6 others (2015) Simulation and analysis of glacier runoff and mass balance in the Nam Co basin, southern Tibetan Plateau. J. Glaciol., 61(227), 447-460

Good E (2015) Daily minimum and maximum surface air temperatures from geostationary satellite data. J. Geophys. Res. Atmos., 120(6), 2306-2324

Guo X and 7 others (2011) Critical evaluation of scalar roughness length parametrizations over a melting valley glacier. Bound.Layer Meteorol., 139(2), 307-332

Guo W and 16 others (2014) The second glacier inventory dataset of China (version 1.0). Cold and Arid Regions Science Data Center, Lanzhou 
Hachem S, Duguay CR and Allard M (2012) Comparison of MODISderived land surface temperatures with ground surface and air temperature measurements in continuous permafrost terrain. Cryosphere, 6(1), 51-69

Hall DK, Key JR, Casey KA, Riggs GA and Cavalieri DJ (2004) Sea ice surface temperature product from MODIS. IEEE Trans. Geosci. Remote Sens., 42(5), 1076-1087

Hall DK, Williams RS, Casey KA, DiGirolamo NE and Wan Z (2006) Satellite-derived, melt-season surface temperature of the Greenland ice sheet (2000-2005) and its relationship to mass balance. Geophys. Res. Lett., 33(11), 156-185

Hall DK and 5 others (2008a) Comparison of satellite-derived and insitu observations of ice and snow surface temperatures over Greenland. Remote Sens. Environ., 112(10), 3739-3749

Hall DK, Williams RS, Luthcke SB and Digirolamo NE (2008b) Greenland ice sheet surface temperature, melt and mass loss: 2000-06. J. Glaciol., 54(184), 81-93

Hock R and Holmgren B (2005) A distributed surface energybalance model for complex topography and its application to Storglaciären, Sweden. J. Glaciol., 51(172), 25-36

Huintjes E and 9 others (2015) Evaluation of a coupled snow and energy balance model for Zhadang glacier, Tibetan Plateau, using glaciological measurements and time-lapse photography. Arctic Antarct. Alp. Res., 47(3), 573-590

Imhoff ML, Zhang P, Wolfe RE and Bounoua L (2010) Remote sensing of the urban heat island effect across biomes in the continental USA. Remote Sens. Environ., 114(3), 504-513

Immerzeel W, Petersen L, Ragettli S and Pellicciotti F (2014) The importance of observed gradients of air temperature and precipitation for modeling runoff from a glacierized watershed in the Nepalese Himalayas. Water Resour. Res., 50(3), 2212-2226

Janatian $\mathrm{N}$ and 6 others (2016) A statistical framework for estimating air temperature using MODIS land surface temperature data. Int. J. Climatol., 37(3), 1181-1194

Jarvis $\mathrm{CH}$ and Stuart N (2001) A comparison among strategies for interpolating maximum and minimum daily air temperatures. Part II: the interaction between number of guiding variables and the type of interpolation method. J. Appl. Meteorol., 40(6), 1075-1084

Kattel DB and 5 others (2013) Temperature lapse rate in complex mountain terrain on the southern slope of the central Himalayas. Theor. Appl. Clim., 113(3), 671-682

Kilibarda M and 6 others (2014) Spatio-temporal interpolation of daily temperatures for global land areas at $1 \mathrm{~km}$ resolution. J. Geophys. Res. Atmos., 119(5), 2294-2313

Kloog I, Nordio F, Coull BA and Schwartz J (2014) Predicting spatiotemporal mean air temperature using MODIS satellite surface temperature measurements across the Northeastern USA. Remote Sens. Environ., 150, 132-139

Koenig LS and Hall DK (2010) Comparison of satellite, thermochron and air temperatures at Summit, Greenland, during the winter of 2008/09. J. Glaciol., 56(198), 735-741

Krishnan P and 6 others (2015) Comparison of in-situ, aircraft, and satellite land surface temperature measurements over a NOAA Climate Reference Network site. Remote Sens. Environ., 165, 249-264

Langer M, Westermann S and Boike J (2010) Spatial and temporal variations of summer surface temperatures of wet polygonal tundra in Siberia - implications for MODIS LST based permafrost monitoring. Remote Sens. Environ., 114(9), 2059-2069

Li QY and Xie ZC (2006) Analyses on the characteristics of the vertical lapse rates of temperature- - taking Tibetan Plateau and its adjacent area as an Example. J. Shihezi Univ. (Nat. Sci.), 24(6), 719-723

Li X and 5 others (2013a) Near-surface air temperature lapse rates in the mainland China during 1962-2011. J. Geophys. Res. Atmos., 118(14), 7505-7515

Li Z-L and 7 others (2013b) Satellite-derived land surface temperature: current status and perspectives. Remote Sens. Environ., 131, 14-37
Li S and 5 others (2014) Evaluation of 10 year AQUA/MODIS land surface temperature with SURFRAD observations. Int. J. Remote Sens., 35(3), 830-856

Liu XD and Chen BD (2000) Climatic warming in the Tibetan Plateau during recent decades. Int. J. Climatol., 20(14), 1729-1742

Liu W and 7 others (2013) A study on temperature lapse rate on the Northern and Southern slopes of the Central Himalayas. J. Arid Meteorol., 31(2), 240-245

Lutz A, Immerzeel W, Shrestha A and Bierkens M (2014) Consistent increase in High Asia's runoff due to increasing glacier melt and precipitation. Nat. Clim. Change, 4(7), 587-592

Machguth H, Paul F, Hoelzle M and Haeberli W (2006) Distributed glacier mass-balance modelling as an important component of modern multi-level glacier monitoring. Ann. Glaciol., 43(1), 335-343

Meyer $\mathrm{H}$ and 6 others (2016) Mapping daily air temperature for Antarctica based on MODIS LST. Remote Sens., 8(9), 732

Min W, Yueqing L and Zhou J (2015) Validation of MODIS land surface temperature products in East of the Qinghai-Xizang Plateau. Plateau Meteorol., 34, 1511-1516

Minder JR, Mote PW and Lundquist JD (2010) Surface temperature lapse rates over complex terrain: lessons from the Cascade Mountains. J. Geophys. Res. Atmos., 115(D14)

Nilsson AG (2009) Near-surface temperature lapse rates over Arctic glaciers and their implications for temperature downscaling. J. Clim., 22(16), 4281-4298

Østby TI, Schuler TV and Westermann S (2014) Severe cloud contamination of MODIS land surface temperatures over an Arctic ice cap, Svalbard. Remote Sens. Environ., 142, 95-102

Oyler JW, Dobrowski SZ, Holden ZA and Running SW (2016) Remotely sensed land skin temperature as a spatial predictor of air temperature across the conterminous United States. J. Appl. Meteorol. Climatol., 55(7), 1441-1457

Pichierri M, Bonafoni S and Biondi R (2012) Satellite air temperature estimation for monitoring the canopy layer heat island of Milan. Remote Sens. Environ., 127, 130-138

Qin J, Yang K, Liang S and Guo X (2009) The altitudinal dependence of recent rapid warming over the Tibetan Plateau. Clim. Change, 97(1), 321

Qiu J (2008) China: the third pole. Nat. News, 454(7203), 393-396

Rolland C (2003) Spatial and seasonal variations of air temperature lapse rates in Alpine regions. J. Clim., 16(7), 1032-1046

Scambos TA, Haran TM and Massom R (2006) Validation of AVHRR and MODIS ice surface temperature products using in situ radiometers. Ann. Glaciol., 44(1), 345-351

Schneider P and 6 others (2009) Satellite observations indicate rapid warming trend for lakes in California and Nevada. Geophys. Res. Lett., 36(22), 355-355

Stahl K, Moore RD, Floyer JA, Asplin MG and McKendry IG (2006) Comparison of approaches for spatial interpolation of daily air temperature in a large region with complex topography and highly variable station density. Agric. For. Meteorol., 139(3-4), 224-236

Stine RA (1995) Graphical interpretation of variance inflation factors. Am. Stat., 49(1), 53-56

Tang RL, Li ZL and Tang BH (2010) An application of the T-s-VI triangle method with enhanced edges determination for evapotranspiration estimation from MODIS data in and and semi-arid regions: implementation and validation. Remote Sens. Environ., 114(3), 540-551

Vancutsem C, Ceccato P, Dinku T and Connor SJ (2010) Evaluation of MODIS land surface temperature data to estimate air temperature in different ecosystems over Africa. Remote Sens. Environ., 114(2), 449-465

Wan Z (2008) New refinements and validation of the MODIS landsurface temperature/emissivity products. Remote Sens. Environ. 112(1), 59-74

Wan Z and Dozier J (1996) A generalized split-window algorithm for retrieving land-surface temperature from space. IEEE Trans. Geosci. Remote Sens., 34(4), 892-905

Wan Z, Zhang Y, Zhang Q and Li Z-L (2002) Validation of the landsurface temperature products retrieved from Terra moderate 
resolution imaging spectroradiometer data. Remote Sens. Environ., 83(1), 163-180

Wang K and Liang S (2009) Evaluation of ASTER and MODIS land surface temperature and emissivity products using long-term surface longwave radiation observations at SURFRAD sites. Remote Sens. Environ., 113(7), 1556-1565

Wang Y and Min W (2014) MODIS/LST product validation for mixed pixels at Linzhi of Tibet. J. Appl. Meteorol. Sci., 25(6)

Wang K and 6 others (2005) Estimation of surface long wave radiation and broadband emissivity using Moderate Resolution Imaging Spectroradiometer (MODIS) land surface temperature/ emissivity products. J. Geophys. Res. Atmos., 110(D11), 139154

Wang W, Liang S and Meyers T (2008) Validating MODIS land surface temperature products using long-term nighttime ground measurements. Remote Sens. Environ., 112(3), 623-635

Wang L, Koike T, Yang K and Yeh PJ-F (2009) Assessment of a distributed biosphere hydrological model against streamflow and MODIS land surface temperature in the upper Tone River Basin. J. Hydrol., 377(1-2), 21-34

Wang NL, Jian-Qiao HE, Hong-Bo WU and Zhen LI (2013a) Spatial variation in spring surface temperature of the Qiumianleiketage glacier in the Kunlun mountains, Tibetan Plateau, and their influencing factors. J. Glaciol. Geocryol., 35(5), 1088-1094

Wang Y, Wang M and Zhao J (2013b) A comparison of MODIS LST retrievals with in situ observations from AWS over the Lambert Glacier Basin, East Antarctica. Int. J. Geosci., 4(3), 611-617

Wang Y, Li G, Min W and Zhang Y (2014) Representativeness analysis of meteorological stations based on temperature estimated from MODIS data. Meteorol. Mon., 40(3), 373-380

Westermann S, Langer M and Boike J (2011) Spatial and temporal variations of summer surface temperatures of high-Arctic tundra on Svalbard - implications for MODIS LST based permafrost monitoring. Remote Sens. Environ., 115(3), 908-922

Westermann S, Langer M and Boike J (2012) Systematic bias of average winter-time land surface temperatures inferred from MODIS at a site on Svalbard, Norway. Remote Sens. Environ., 118, 162-167

Williamson SN, Hik DS, Gamon JA, Kavanaugh JL and Koh S (2013) Evaluating cloud contamination in clear-sky MODIS Terra daytime land surface temperatures using ground-based meteorology station observations. J. Clim., 26(5), 1551-1560

Wu Y, Wang N, He J and Jiang X (2015) Estimating mountain glacier surface temperatures from Landsat-ETM+ thermal infrared data: a case study of Qiyi glacier, China. Remote Sens. Environ., 163, 286-295

Xu Y and Shen Y (2013) Reconstruction of the land surface temperature time series using harmonic analysis. Comput. Geosci., 61(4), 126-132

Xu YM, Qin ZH and Shen Y (2012) Study on the estimation of nearsurface air temperature from MODIS data by statistical methods. Int. J. Remote Sens., 33(24), 7629-7643
Xu Y, Knudby A and Ho HC (2014) Estimating daily maximum air temperature from MODIS in British Columbia, Canada. Int. J. Remote Sens., 35(24), 8108-8121

Yang W and 6 others (2011) Summertime surface energy budget and ablation modeling in the ablation zone of a maritime Tibetan glacier. J. Geophys. Res. Atmos., 116(D14)

Yao T and 9 others (2012) Third pole environment (TPE). Environ. Dev., 3, 52-64

Yu W and Ma M (2011) Validation of the MODIS land surface temperature products - a case study of the Heihe River Basin. Remote Sens. Technol. Appl., 26(6), 705-712

Yu W, Wu T, Nan Z, Zhao L and Wang Z (2014) A novel interpolation method for MODIS land surface temperature data on the Tibetan Plateau. Proc. SPIE - Int. Soc. Opt. Eng., 9260, 92600Y-92600Y-10

Yu J and 6 others (2016) Developing daily cloud-free snow composite products from MODIS Terra-Aqua and IMS for the Tibetan Plateau. IEEE Trans. Geosci. Remote Sens., 54(4), 2171-2180

Zhang W, Huang Y, Yu YQ and Sun WJ (2011) Empirical models for estimating daily maximum, minimum and mean air temperatures with MODIS land surface temperatures. Int. J. Remote Sens., 32 (24), 9415-9440

Zhang Y, Hirabayashi Y and Liu S (2012) Catchment-scale reconstruction of glacier mass balance using observations and global climate data: case study of the Hailuogou catchment, southeastern Tibetan Plateau. J. Hydrol., 444, 146-160

Zhang L, Su F, Yang D, Hao Z and Tong K (2013) Discharge regime and simulation for the upstream of major rivers over Tibetan Plateau. J. Geophys. Res. Atmos., 118(15), 8500-8518

Zhang G and 6 others (2014) Estimating surface temperature changes of lakes in the Tibetan Plateau using MODIS LST data. J. Geophys. Res. Atmos., 119(14), 8552-8567

Zhang F and 8 others (2015) Snow cover and runoff modelling in a high mountain catchment with scarce data: effects of temperature and precipitation parameters. Hydrol. Process., 29(1), 52-65

Zhang H, Zhang F, Ye M, Che T and Zhang G (2016a) Estimating daily air temperatures over the Tibetan Plateau by dynamically integrating MODIS LST data. J. Geophys. Res. Atmos., 121(19), $11,425-11,441$

Zhang H, Zhang F, Zhang G, He X and Tian L (2016b) Evaluation of cloud effects on air temperature estimation using MODIS LST based on ground measurements over the Tibetan Plateau. Atmos. Chem. Phys., 16(21), 13681-13696

Zhou J and 5 others (2015) Exploring the water storage changes in the largest lake (Selin Co) over the Tibetan Plateau during 2003-2012 from a basin-wide hydrological modeling. Water Resour. Res., 51(10), 8060-8086

Zhu W, Lû A and Jia S (2013) Estimation of daily maximum and minimum air temperature using MODIS land surface temperature products. Remote Sens. Environ., 130, 62-73

Zhu W, Lû A, Jia S, Yan J and Mahmood R (2017) Retrievals of all-weather daytime air temperature from MODIS products. Remote Sens. Environ., 189, 152-163 